\title{
Assessment of Arctic and Antarctic sea ice predictability in CMIP5 decadal hindcasts
}

\author{
Chao-Yuan Yang ${ }^{1}$, Jiping Liu ${ }^{1}$, Yongyun $\mathrm{Hu}^{2}$, Radley M. Horton ${ }^{3}$, Liqi Chen ${ }^{4}$, and Xiao Cheng ${ }^{5}$ \\ ${ }^{1}$ Department of Atmospheric and Environmental Sciences, University at Albany, State University of New York, \\ Albany, NY, USA \\ ${ }^{2}$ Department of Atmospheric and Oceanic Sciences, School of Physics, Peking University, Beijing, China \\ ${ }^{3}$ Columbia University Center for Climate Systems Research and NASA Goddard Institute for Space Studies, \\ New York, NY, USA \\ ${ }^{4}$ Key Laboratory of Global Change and Marine-Atmospheric Chemistry, Third Institute of Oceanography, SOA, \\ Xiamen, China \\ ${ }^{5}$ College of Global Change and Earth System Science, Beijing Normal University, Beijing, China
}

Correspondence to: Chao-Yuan Yang (cyang4@albany.edu)

Received: 23 April 2016 - Published in The Cryosphere Discuss.: 10 May 2016

Revised: 13 August 2016 - Accepted: 8 September 2016 - Published: 21 October 2016

\begin{abstract}
This paper examines the ability of coupled global climate models to predict decadal variability of Arctic and Antarctic sea ice. We analyze decadal hindcasts/predictions of 11 Coupled Model Intercomparison Project Phase 5 (CMIP5) models. Decadal hindcasts exhibit a large multimodel spread in the simulated sea ice extent, with some models deviating significantly from the observations as the predicted ice extent quickly drifts away from the initial constraint. The anomaly correlation analysis between the decadal hindcast and observed sea ice suggests that in the Arctic, for most models, the areas showing significant predictive skill become broader associated with increasing lead times. This area expansion is largely because nearly all the models are capable of predicting the observed decreasing Arctic sea ice cover. Sea ice extent in the North Pacific has better predictive skill than that in the North Atlantic (particularly at a lead time of 3-7 years), but there is a reemerging predictive skill in the North Atlantic at a lead time of 6-8 years. In contrast to the Arctic, Antarctic sea ice decadal hindcasts do not show broad predictive skill at any timescales, and there is no obvious improvement linking the areal extent of significant predictive skill to lead time increase. This might be because nearly all the models predict a retreating Antarctic sea ice cover, opposite to the observations. For the Arctic, the predictive skill of the multi-model ensemble mean outperforms most models and the persistence
\end{abstract}

prediction at longer timescales, which is not the case for the Antarctic. Overall, for the Arctic, initialized decadal hindcasts show improved predictive skill compared to uninitialized simulations, although this improvement is not present in the Antarctic.

\section{Introduction}

Decadal climate prediction is a new and rapidly evolving research area driven by societal demand for climate information to inform climate adaptation strategies (e.g., Meehl et al., 2009, 2013; Vera et al., 2010). As a boundary between the ocean and atmosphere, sea ice plays an important role in the climate system and acts as an important indicator of climate change through dynamic and thermodynamic processes and various feedbacks (i.e., albedo, insulation, and buoyancy). Thus, sea ice simulation and prediction is one of the most challenging and important issues in decadal climate prediction (e.g., Meehl et al., 2009).

In the past few decades, Arctic sea ice has been declining (e.g., Serreze et al., 2007; Jeffries et al., 2015). Trends in Arctic sea ice extent are negative for all months (e.g., Comiso et al., 2008; Comiso, 2012; Cavalieri and Parkinson, 2012), largely due to thinning and loss of the perennial sea ice cover (Kwok et al., 2009), but are largest at the end of the summer 


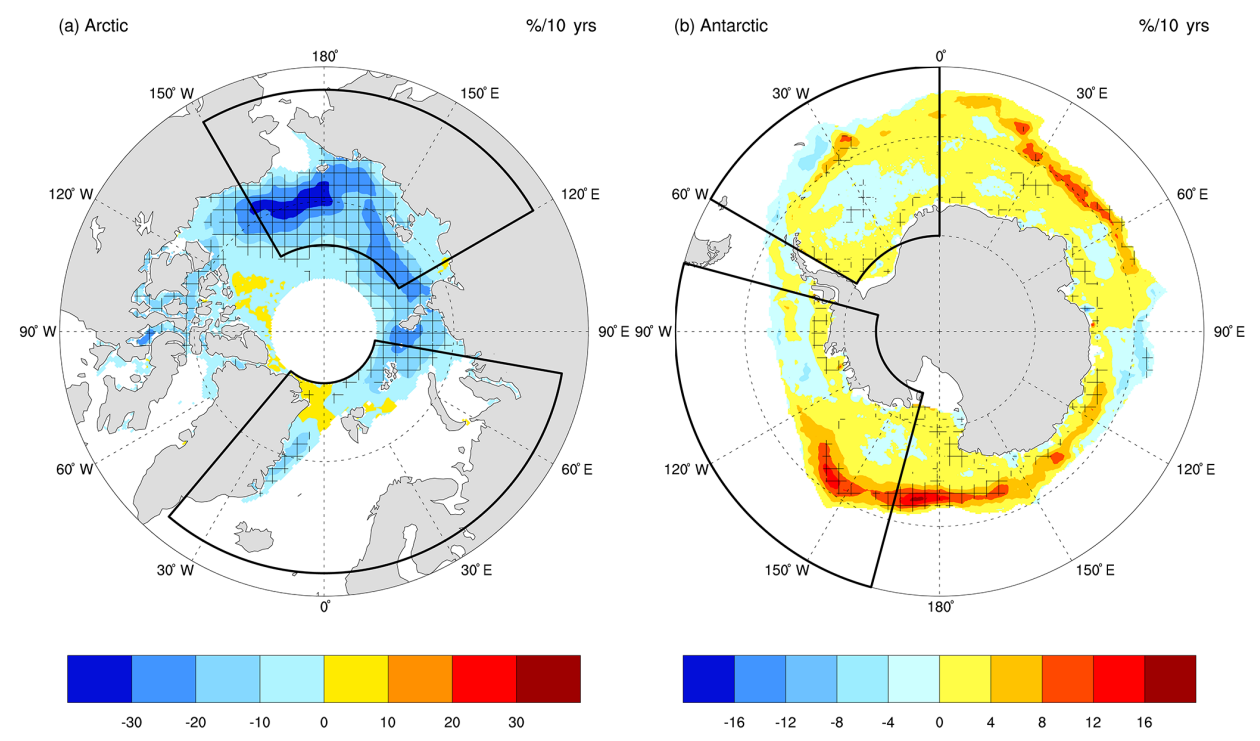

Figure 1. Linear trends of September sea ice concentration for (a) Arctic and (b) Antarctic during the period of 1979-2014. The meshed areas denote the trends above $95 \%$ confidence level. Boxes indicate the areas used to generate the regional sea ice indices.

melt season. September Arctic sea ice extent has declined by $0.87 \times 10^{6} \mathrm{~km}^{2}$ for the period 1979-2014, with a pronounced decreasing trend of sea ice concentrations in the arc extending from the Beaufort Sea to the Barents Sea (> $95 \%$ significance, Fig. 1a). The possibility of an ice-free Arctic in the coming decades (Stroeve et al., 2007, 2012; Boé et al., 2009; Wang and Overland, 2009, 2012; Zhang, 2010; Massonnet et al., 2012; Liu et al., 2013) would have profound impacts on Arctic maritime activities (e.g., opening of shorter shipping routes) and ecosystems (e.g., changing solar radiation in the upper ocean and influencing primary productivity), and extreme weather and climate at midlatitudes and high latitudes (e.g., Liu et al., 2012; Francis and Vavrus, 2012; Smith and Stephenson, 2013; Jung et al., 2013; Stroeve et al., 2014b).

By contrast, Antarctic sea ice has been expanding (e.g., Liu et al., 2004; Turner et al., 2009; Comiso et al., 2011; Parkinson and Cavalieri, 2012). Trends in Antarctic sea ice extent are positive for all months. Unlike the almost uniform Arctic sea ice decreases, the trends in Antarctic sea ice concentrations show strong regional variations, although NASA's Ice, Cloud, and land Elevation Satellite showed that Antarctic sea ice thickness had a small negative trend during 2003-2008 (Kurtz and Markus, 2012). September Antarctic sea ice extent increased by $0.24 \times 10^{6} \mathrm{~km}^{2}$ per decade during 1979-2014, with a pronounced positive trend of sea ice concentrations in the Ross Sea partially offset by a negative trend in the Bellingshausen and Weddell seas (Fig. 1b). The limited understanding of some of the mechanisms responsible for the observed decrease (increase) in Arctic (Antarctic) sea ice makes sea ice prediction challenging (e.g., Kattsov et al., 2010; Richter-Menge et al., 2012; Bindoff et al., 2013; Goosse et al., 2015).
Most sea ice predictability studies have focused on the Arctic and the seasonal to interannual timescale. An outlook of September Arctic sea ice extent has been obtained from the research community since 2008. Stroeve et al. (2014a) showed that the median July (the same was true for June and August) prediction value for September sea ice cover was off by a large margin in 2009, 2012 (record low), and 2013. Koenigk and Mikolajewicz (2009) suggested sea ice cover has low predictability in the central Arctic but some predictability at sea ice edge zones in the MPI ECHAM5OM climate model. Holland et al. (2011) showed potential predictability of sea ice cover with a few months lead time in the NCAR Community Climate System Model version 3 (CCSM3). They also suggested that the persistence of sea ice thickness anomalies is much higher than that of sea ice extent anomalies, which might point to a pathway towards greater predictability as models improve their simulation of sea ice thickness. Predictability of sea ice cover with e-folding timescales of 2-5 months has been identified in several climate models (Day et al., 2014a). A few modeling studies also showed continuous predictability of sea ice cover for 1-2 years, and intermittent predictability for 2-4 years (Blanchard-Wrigglesworth et al., 2011b; Day et al., 2016; Tietsche et al., 2013, 2014; Guemas et al., 2016). In contrast to the Arctic, there are limited efforts on examining predictability of Antarctic sea ice. Using the NCAR CCSM3 model, Holland et al. (2013) showed initial-value predictability of sea ice for a few months on the sea ice around Antarctica.

To date, relatively little attention has been paid to assessing the prediction skill of sea ice at decadal timescales for the Arctic and Antarctic in present-day climate models. Decadal 
sea ice prediction entails a combination of initial value and climate forcing issues. At decadal timescales, internal climate variability affects sea ice (i.e., some aspects of climate internal variability may be predictable; Collins and Allen, 2002; Smith et al., 2007; Keenlyside et al., 2008; Meehl et al., 2009; Pohlmann et al., 2009; Mochizuki et al., 2012), as do prescribed external scenarios (e.g., greenhouse gases and other radiatively important agents). Blanchard-Wriggleworth et al. (2011b) suggested that predictability of Arctic sea ice beyond 3 years is largely influenced by climate forcing rather than initial values. The growing dominance of climate forcings is likely to introduce some potential predictability since it accounts for increasingly large portions of sea ice change from present conditions (e.g., National Research Council, 2012). Guemas et al. (2016) also underlined that predicting future change of Arctic sea ice on decadal timescales is challenging due to initialization problems (i.e., the initial shocks due to sparse observations, limitations of reanalysis data, and ensemble generation methods).

The recent Coupled Model Intercomparison Project Phase 5 (CMIP5) has implemented an experimental framework to simulate and predict decadal climate variability (Meehl et al., 2009; Taylor et al., 2012) in support of the Intergovernmental Panel in Climate Change Fifth Assessment Report. The evaluation of decadal hindcasts is an important step for improving decadal predictions since it can elucidate issues in initialization methods and model responses to natural variability and climate forcings. In this study, we examine the capability of CMIP5 decadal hindcasts to simulate the mean and decadal variability of Arctic and Antarctic sea ice extent.

\section{Models and data}

Eleven CMIP5 models are used to evaluate the decadal hindcast/prediction of sea ice in both the Arctic and Antarctic. These 11 models provide a set of 10-year-long hindcast simulations, which was initialized every 5 years from 1981 to 2006. The purpose of initialization is to start coupled global climate models close to the most realistic possible sea ice state. In general, the initialization for the CMIP5 decadal hindcast/prediction can be divided into two approaches, full initialization and anomaly initialization. For the full initialization approach, the initial model state is replaced by the best available estimate of the observed sea ice state (i.e., satellite observation and ocean analysis). This efficiently reduces the initial error due to the systematic bias in the presence of model deficiencies. However, as the model is integrated for the decadal hindcast/prediction, the simulation tends to drift away from the best-estimated sea ice state no matter how small the initial error is. The anomaly initialization approach partly addresses this problem by assimilating observed sea ice anomalies on the modeled sea ice state with a focus on predicting future sea ice anomalies.
Table 1 provides a summary of the initialization approaches and data source of the initial sea ice state for each individual model. We note that four models (CanCM4, CFSv2, GEOS-5, and HadCM3) assimilate observed sea ice concentrations from different resources into their sea ice initial conditions (hereafter referred to as direct sea ice initialization), whereas the rest of the models constrain sea ice initial conditions through assimilating observed ocean variables (i.e., temperature), in which the sea ice initial condition is indirectly influenced by different ocean assimilation approaches (hereafter referred to as indirect sea ice initialization). Note that the direct vs. indirect initialization is different from the aforementioned full-field vs. anomaly initialization. More detailed information about the setup of the decadal experiment can be found in Meehl et al. (2009) and Taylor et al. (2012). For each individual model, all ensemble members of the 10-year-long hindcast/prediction that are archived at http://cmip-pcmdi.llnl.gov/cmip5/data_portal.html are used (see Table 1 for more information). Each ensemble member was generated by slightly different initial conditions. Here we focus on September Arctic (seasonal minimum) and Antarctic (seasonal maximum) sea ice. The reasons that we focus on September Antarctic sea ice, rather than the month of seasonal minimum like the Arctic, are that (1) sea ice in the Antarctic largely melts away (confined to coastal Antarctica) during the seasonal minimum (i.e., February or March), (2) previous studies (e.g., Turner et al., 2013; Meijers, 2014) have shown that climate models poorly simulate the seasonal minimum, and (3) September sea ice extent has a significant increasing trend.

Satellite-derived sea ice extent and concentration in the Arctic and Antarctic are used to evaluate the CMIP5 decadal hindcast. They are obtained from the National Snow and Ice Data Center, and are derived from the Nimbus-7 Scanning Multichannel Microwave Radiometer (SSMR), DMSP Special Sensor Microwave/Imager (SSM/I), and Special Sensor Microwave Imager and Sounder (SSMIS) sensors (Comiso, 2015; Fetterer et al., 2002, 2010). Because the observation and models have different horizontal resolution (see details in Table 1), before performing the assessment we interpolate all the data (satellite observation and model simulations) to a horizontal resolution of $1^{\circ}$. The multi-model ensemble mean (MMEM) is calculated based on the equally weighted average of 69 total ensemble members (Table 1).

\section{Prediction skill of CMIP5 decadal hindcasts}

\subsection{Arctic sea ice}

We evaluate the model simulation and prediction skill by comparing sea ice extent between each individual model and satellite observations. Figure 2 shows the time series of September Arctic sea ice extent from the simulation of the 10 -year hindcast for each model and the observation from 
Table 1. Summary of initialization methods and data sources used for the CMIP5 decadal hindcast/prediction.

\begin{tabular}{|c|c|c|c|c|}
\hline Model & $\begin{array}{l}\text { Resolution } \\
\text { (sea ice model) }\end{array}$ & $\begin{array}{l}\text { Ensemble } \\
\text { members }\end{array}$ & $\begin{array}{l}\text { Initialization } \\
\text { date }\end{array}$ & $\begin{array}{l}\text { Sea ice assimilation method } \\
\text { and data source }\end{array}$ \\
\hline BCC-CM1.1 & 1 long $\times 1-1 / 3$ lat & 4 & 1 January & $\begin{array}{l}\text { Indirect full-field sea ice initialization (the initial sea ice } \\
\text { indirectly influenced by nudging } T \text { to SODA ocean reanalysis) }\end{array}$ \\
\hline CanCM4 & $\sim 2.8$ long $\times 2.8$ lat & 10 & 1 January & $\begin{array}{l}\text { Direct full-field sea ice initialization (SIC from HadISST1.1 } \\
\text { and SIT from model-based climatology; Merryfield et al., 2013) }\end{array}$ \\
\hline CCSM4 & 0.9 long $\times 1.25$ lat & 10 & 1 January & $\begin{array}{l}\text { Indirect full-field sea ice initialization (the initial sea ice indirectly } \\
\text { influenced by bias-corrected CORE2-forced ocean hindcast) }\end{array}$ \\
\hline CFSv2 & 0.5 long $\times 0.5$ lat & 4 & 1 November & $\begin{array}{l}\text { Direct full-field sea ice initialization } \\
\text { (SIC from NCEP climate forecast system reanalysis) }\end{array}$ \\
\hline FGOALS-g2 & 1 long $\times 1$ lat & 3 & 1 January & $\begin{array}{l}\text { Indirect full-field sea ice initialization (the initial sea ice indirectly } \\
\text { influenced by nudging } T \text { and } S \text { to an ocean reanalysis) }\end{array}$ \\
\hline GEOS-5 & 1 long $\times 1$ lat & 3 & 1 January & $\begin{array}{l}\text { Direct full-field sea ice initialization } \\
\text { (SIC from GEOS-iODAS) }\end{array}$ \\
\hline GFDL-CM2.1 & $\sim 1$ long $\times 0.75$ lat & 10 & 1 January & $\begin{array}{l}\text { Indirect full-field sea ice initialization (the initial sea ice indirectly } \\
\text { influenced by atmospheric and ocean data; Msadek et al., 2014) }\end{array}$ \\
\hline HadCM3 & 1.25 long $\times 1.25$ lat & 10 & 1 November & $\begin{array}{l}\text { Direct anomaly sea ice initialization (SIC from } \\
\text { Met Office Hadley Centre sea ice data, HadISST) }\end{array}$ \\
\hline IPSL-CM5A-LR & $\sim 2$ long $\times 2$ lat & 6 & 1 January & $\begin{array}{l}\text { Indirect anomaly sea ice initialization (the initial sea ice indirectly } \\
\text { influenced by the assimilation of } T \text { and } S \text { anomalies from observations) }\end{array}$ \\
\hline MIROC5 & 1 long $\times 1$ lat & 6 & 1 January & $\begin{array}{l}\text { Indirect anomaly sea ice initialization (the initial sea ice is indirectly } \\
\text { influenced by the assimilation of } T \text { and } S \text { from an objective analysis of } \\
\text { Ishii and Kimoto, 2009) }\end{array}$ \\
\hline MPI-ESM-MR & $\sim 0.4$ long $\times 0.4$ lat & 3 & 1 January & $\begin{array}{l}\text { Indirect anomaly sea ice initialization (the initial sea ice indirectly } \\
\text { influenced by the assimilation of } T \text { and } S \text { anomalies from a forced ocean } \\
\text { run using NCEP reanalysis; Müller et al., 2012) }\end{array}$ \\
\hline
\end{tabular}

SIC: sea ice concentration, SIT: sea ice thickness, $T$ : ocean temperature, $S$ : salinity.

1981 to 2015 . It is immediately apparent that the models exhibit very different magnitudes of September sea ice extent. CanCM4, CFSv2, GEOS-5, and GFDL-CM2.1 simulate a smaller ice extent compared to the observation during the entire period; CFSv2 has the least sea ice cover of any of the models. By contrast, BCC-CSM1.1, CCSM4, FGOALS-g2, and MIROC5 simulate a larger ice extent. The simulated ice extent of HadCM3, IPSL-CM5A-LR, and MPI-ESM-MR is comparable to the observations, but they cannot reproduce the anomalously low sea ice cover since 2007 (i.e., record lows in 2007 and 2012). We note that the models that are initialized with values close to various estimates of sea ice state (direct and indirect full-field initialization, see Table 1) drift towards their modeled sea ice state within a few years of integration, particularly BCC-CSM1.1, CanCM4, CCSM4, CFSv2, and FGOALS-g2. Hence initializations with values from various best estimates of sea ice state do not necessarily mitigate drift, although they significantly reduce the model bias at the initial step. By contrast, the models that are initialized with various estimates of sea ice anomaly (direct and indirect anomaly initialization) tend to have smaller drift problems during the integration.
To quantify the skill of each individual model and MMEM in predicting the evolution of sea ice, we calculate the anomaly correlation coefficient (ACC) between the predicted and observed September sea ice concentration anomaly in each grid box as follows.

$$
\mathrm{ACC}=\frac{\sum_{i=1}^{n}[P(i, t)-\bar{P}(t)] \cdot[O(i, t)-\bar{O}(t)]}{\sqrt{\sum_{i=1}^{n}[P(i, t)-\bar{P}(t)]^{2} \cdot \sum_{i=1}^{n}[O(i, t)-\bar{O}(t)]^{2}}},
$$

where $P$ is the predicted sea ice concentration and $\bar{P}(t)$ is calculated as $\sum_{i=1}^{n} P(i, t) / n ; O$ is the observed sea ice concentration and $\bar{O}(t)$ is calculated as $\bar{O}(t)=\sum_{i=1}^{n} O(i, t) / n . i$ is the start year and $t$ is the lead year. Here the ACCs of the ensemble mean of each individual model and MMEM for lead times of 1,3-5, and 6-8 years are discussed. For example, for the lead time of 3-5 years, the data for the 1981 initialization are the average value of 1983-1985, the data for the 1986 initialization are the average value of $1988-1990$, and so on. 

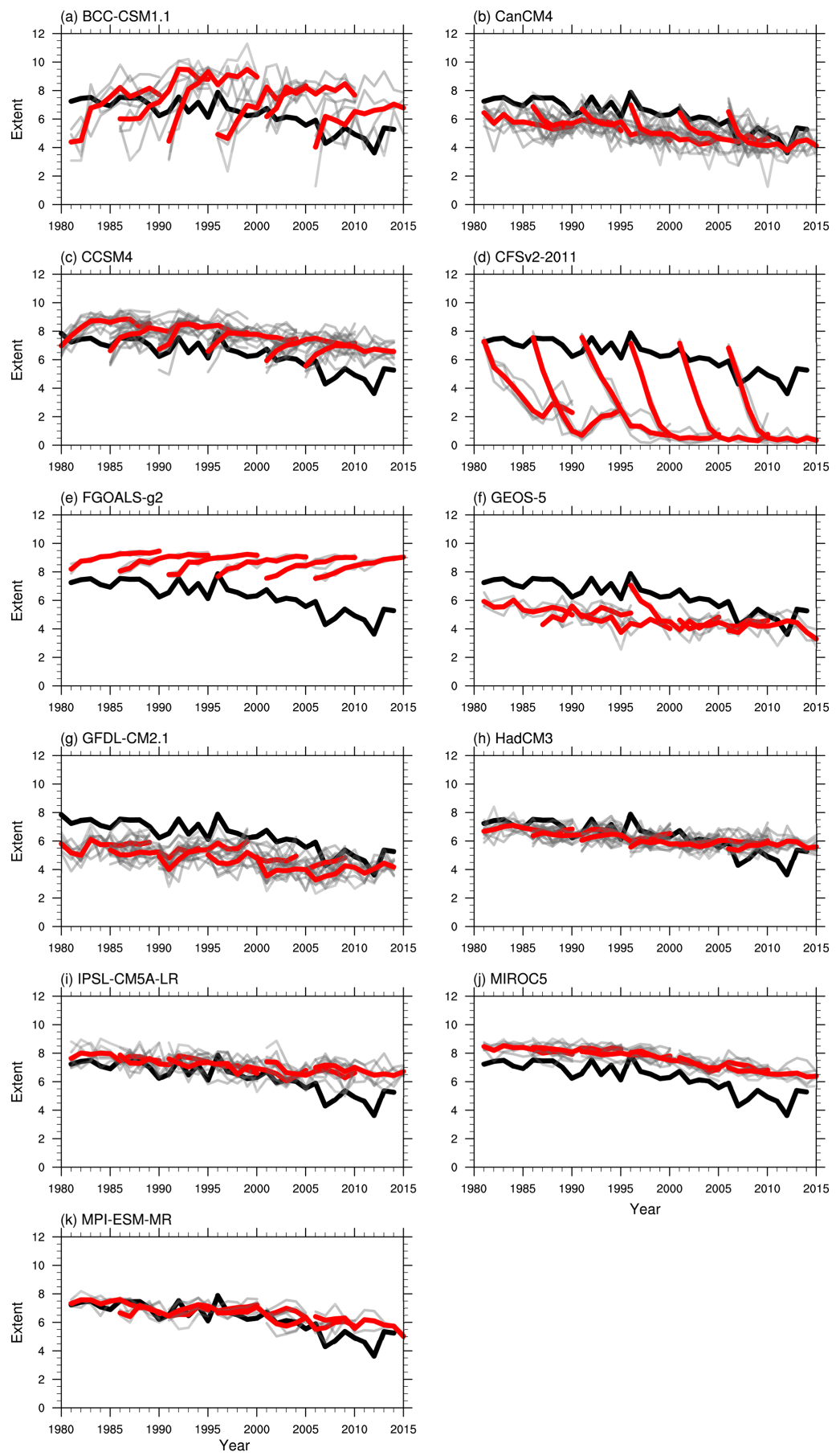

Figure 2. Time series of September Arctic sea ice extent (seasonal minimum) from the simulations of the 10-year hindcast for each ensemble member of each individual model (thin gray line), the ensemble mean of each individual model (thick red line), and satellite observation (black line) from 1981 to 2015.

This means the adjacent data points in the time series have a time interval of 5 years, and this time series is compared to the average of the same 3 years in the observations.

For the lead time of 1 year, for some models, only scattered predictive skill ( $>95 \%$ significance) in forecasting September sea ice concentration anomalies is found, generally in the arc around the periphery of the Arctic Basin, extending from the north of Alaska to the northeast of Siberia (top panel of Fig. 3). The MMEM shows small clustered areas of significant ACCs between the Beaufort and eastern Siberian seas, whereas areas near the central Arctic Ocean have the least predictive skill (negative ACCs; Fig. 31 in the top panel). In 
1 year

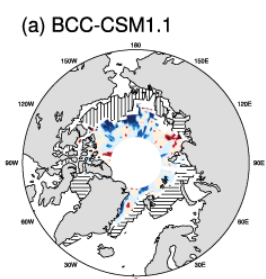

(e) FGOALS-g2

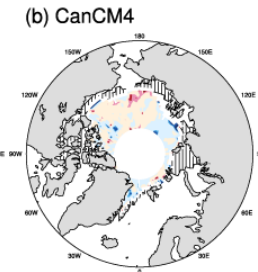

(c) CCSM4

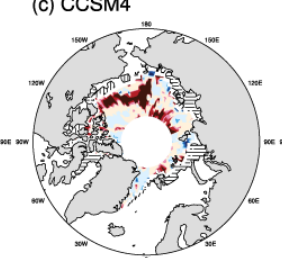

(g) GFDL-CM⒉1

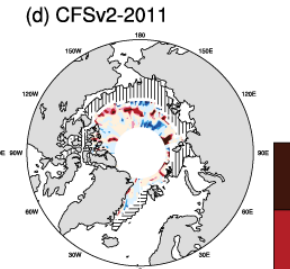

0.88

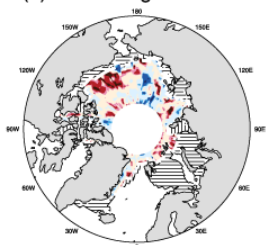

(f) GEOS-5

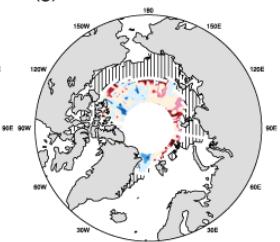

(h) $\mathrm{HadCM} 3$

0.73

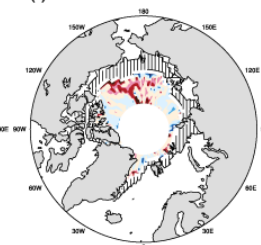

(j) MIROC5

(k) MPI-ESM-MR

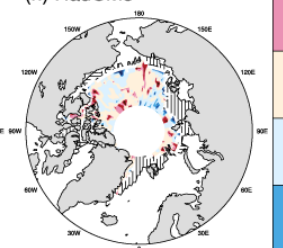

0.61

(i) IPSL-CM5A-LR
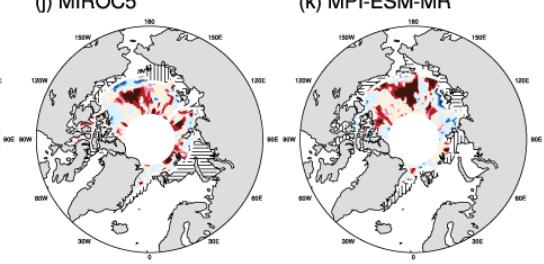

(I) MMEM

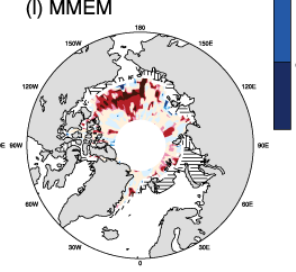

0

$-0.61$

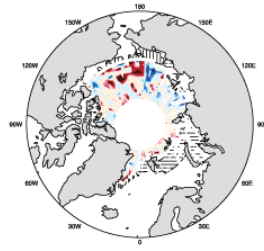

3-5 years

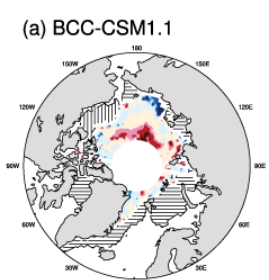

(e) FGOALS-g2
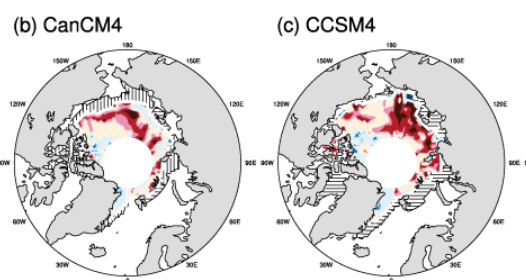

(f) GEOS-5

(g) GFDL-CM2.1

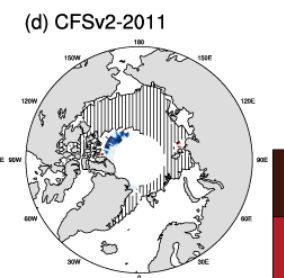

0.88
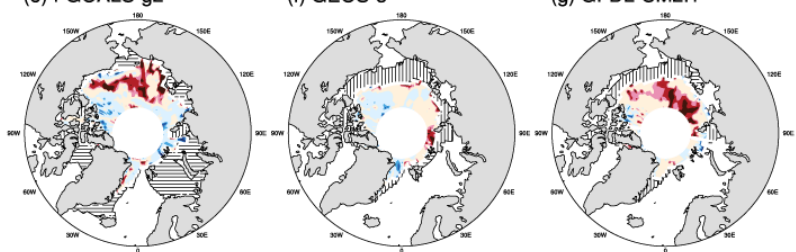

(h) $\mathrm{HadCM} 3$

0.73

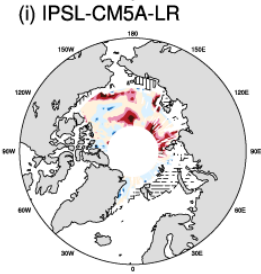

(j) MIROC5

(k) MPI-ESM-MR

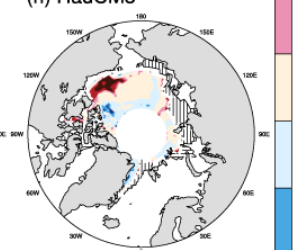

0.61

0
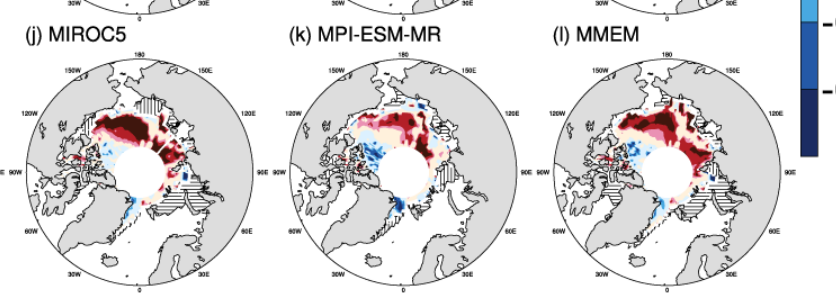

$-0.73$

$-0.88$

Figure 3. Anomaly correlation coefficients between the simulated and observed Arctic September sea ice concentration anomalies for the lead time of 1 year (top panel) and 3-5 years (bottom panel). The correlation coefficients of $0.61,0.73$, and 0.88 represent 90,95 , and $99 \%$ confidence levels, respectively. Horizontal lines depict the areas where the model simulation has sea ice, whereas the observation does not have sea ice. The opposite is the case for vertical lines.

general, the areas of significant ACCs in CCSM4, MIROC5, and MPI-ESM-MR are similar to that of the MMEM.

For the lead time of 3-5 years, the areas of significant predictive skill become broader for the majority of the mod- els compared to those of 1 year, covering large parts of the northern Beaufort, Chukchi, eastern Siberian, and Laptev seas (bottom panel of Fig. 3). The exceptions are CFSv2 and GEOS-5. CFSv2 has too little sea ice cover in the Arctic 
Ocean due to the aforementioned drift problem. The ACCs of GEOS-5 for the lead time of 3-5 year are even smaller than those of 1 year for the area of ACCs exceeding the $95 \%$ confidence level. The MMEM shows large clustered areas of significant ACCs in the arc around the Arctic Basin, extending from the north of Alaska to the north of Siberia (Fig. 31 in the bottom panel). Again, the central Arctic Ocean towards the Canadian Archipelago and northern Greenland Sea shows the least predictive skill.

The results for the lead time of 6-8 years are broadly similar to those of the lead time of 3-5 years, although the areas of significant predictive skill are relatively broader for the majority of the models (not shown). The MMEM also shows enlarged areas of significant ACCs relative to those of 3-5 years, i.e., along the eastern coast of Greenland (not shown). In general, the MMEM has better predictive skill than the majority of the models for all lead times.

Figure 4 shows the predicted trend (slope of a linear regression) as a function of lead times after applying a 3-year average to filter out high-frequency variability. For each individual model, the trend is calculated based on its ensemble mean (see no. of ensemble members in Table 1). All the models reproduce the observed negative trend, except that BCC-CSM1.1 has a positive trend at the lead time of $1-3$ and $2-4$ years. However, the simulated negative trends show very different magnitude, ranging from about -0.2 to $-0.9 \times 10^{6} \mathrm{~km}^{2}$ per decade. Compared to the observation, there is a systematic underestimation of the decreasing trend throughout the integration period for all decadal hindcasts. This is particularly true for the lead time of $6-$ 8 and $7-9$ years (i.e., about $-0.6 \times 10^{6} \mathrm{~km}^{2}$ per decade for the MMEM vs. $-1.2 \times 10^{6} \mathrm{~km}^{2}$ per decade for the observation) because those longer lead times are weighted towards inclusion of more data points in recent years (the years with accelerated decline of Arctic sea ice).

To figure out to what extent the identified areas with significant ACCs at different lead times are caused by the decadal decreasing trend, we remove the linear trend in the predicted and observed sea ice concentration in each grid box. As shown in Fig. 5, after the trend is removed, the areas with significant ACCs become much smaller relative to those of Fig. 3, especially for the lead time of 3-5 and 6-8 years. This suggests that high predictability found in Fig. 3 at longer timescales is largely due to the decreasing Arctic sea ice in recent decades. Thus the relatively long prediction skill over the areas of the northern Beaufort, Chukchi, eastern Siberian, and Laptev seas is influenced by long-term sea ice reduction.

To further examine the prediction skill of Arctic sea ice variability in the context of regional climate variability, we generate three sea ice extent indices: (1) the entire Arctic, (2) the North Pacific, and (3) the North Atlantic. Sea ice variability in the North Pacific and North Atlantic is modulated by different dominant decadal oscillations. Previous studies suggested that sea ice in the Bering and Beaufort seas is correlated with the Pacific Decadal Oscillation (PDO), which

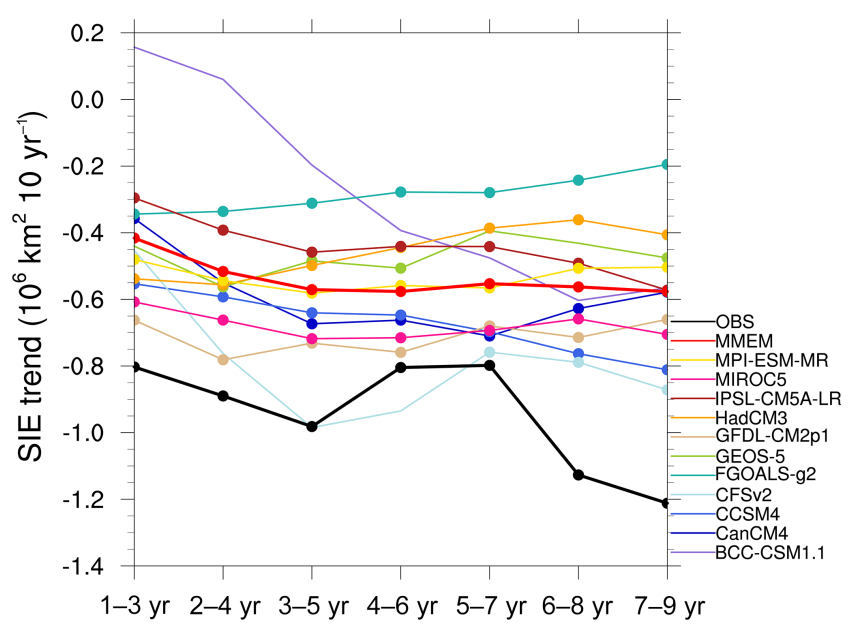

Figure 4. The predicted trends (slope of a linear regression) of September Arctic sea ice extent (SIE) anomalies as a function of the lead time after applying a 3-year average. The dots represent the trends exceeding $95 \%$ confidence level.

has undergone a transition from a dominantly positive phase to a more negative phase in recent decades (Lindsay and Zhang, 2005; Zhang et al., 2010; Wendler et al., 2014). Sea ice in the North Atlantic, particularly the ice export through the Fram Strait and import from the Barents Sea, is significantly affected by the phases of the North Atlantic Oscillation (e.g., Kwok, 2000; Rigor and Wallace, 2004). Enfield et al. (2001) linked North Atlantic sea ice variability to the Atlantic Multidecadal Oscillation (AMO) using the time frequency analysis of historical and paleo records. Day et al. (2012) suggested that up to $30 \%$ of the North Atlantic sea ice decline during 1979-2010 might be attributed to the natural cycle of the AMO by analyzing five CMIP3 models.

In Fig. 3, horizontal lines denote the areas where the model simulation has sea ice, whereas the observation does not have sea ice. The opposite is the case for vertical lines. For the Pacific sector of the Arctic, there is no sea ice in the Bering Sea in September for any model simulations. The models that are positively biased in September simulate too much sea ice in the Barents Sea. Here we define the North Pacific sea ice index as the total September sea ice extent in the Chukchi, East Siberian, and Laptev seas $\left(120^{\circ} \mathrm{E}-150^{\circ} \mathrm{W}\right.$ and $62.5-$ $80^{\circ} \mathrm{N}$ ). The North Atlantic sea ice index is defined as the total September sea ice extent in the Greenland, Norwegian, and Barents seas $\left(40^{\circ} \mathrm{W}-80^{\circ} \mathrm{E}\right.$ and $62.5-84^{\circ} \mathrm{N}$; see boxes in Fig. 1). A 3-year average is also applied to these indices.

The predictive skill for these indices is also measured by the anomaly correlation coefficient between the model hindcast and observation. Figure 6 shows the ACC as a function of lead times for the ensemble mean of each individual model and MMEM. To provide additional perspective on the relative skill of the decadal experiments, the anomaly correlation coefficient of the persistence prediction is also shown. 
1 year

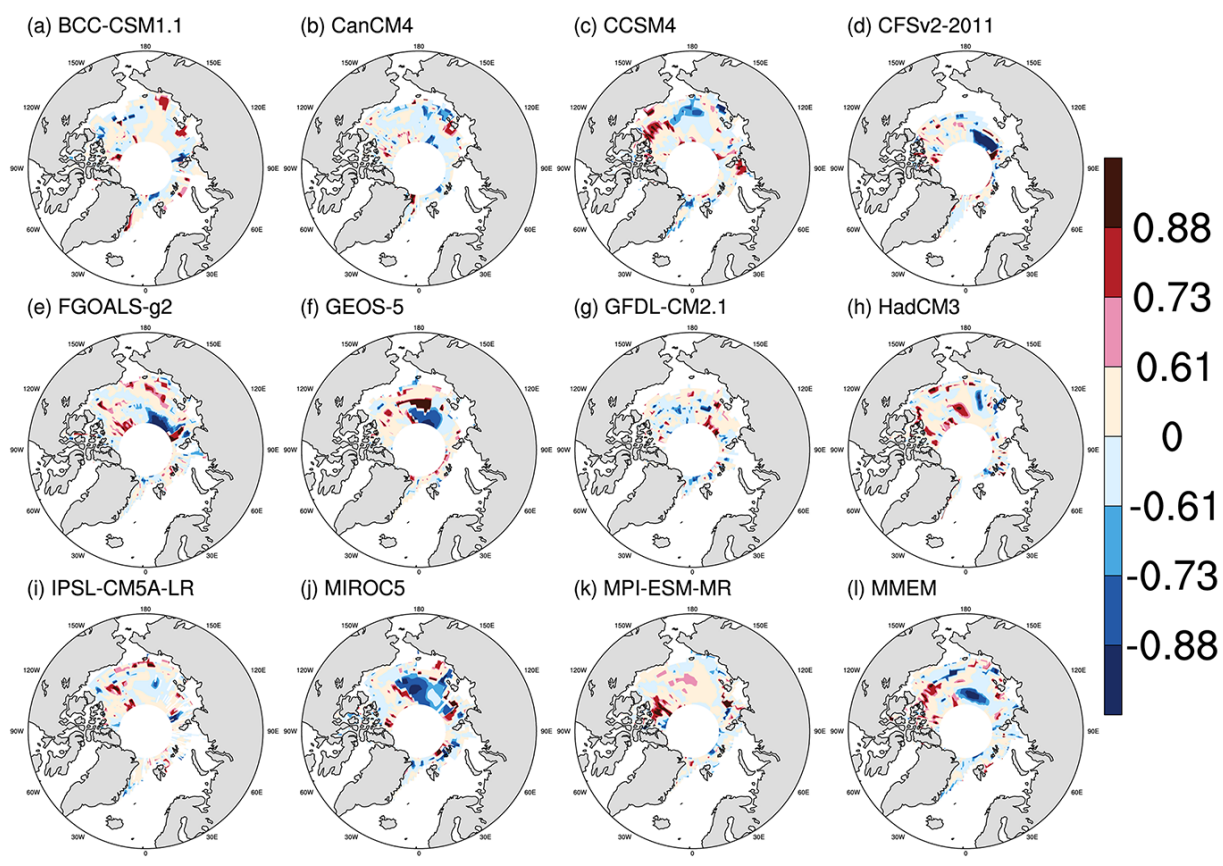

$3-5$ years

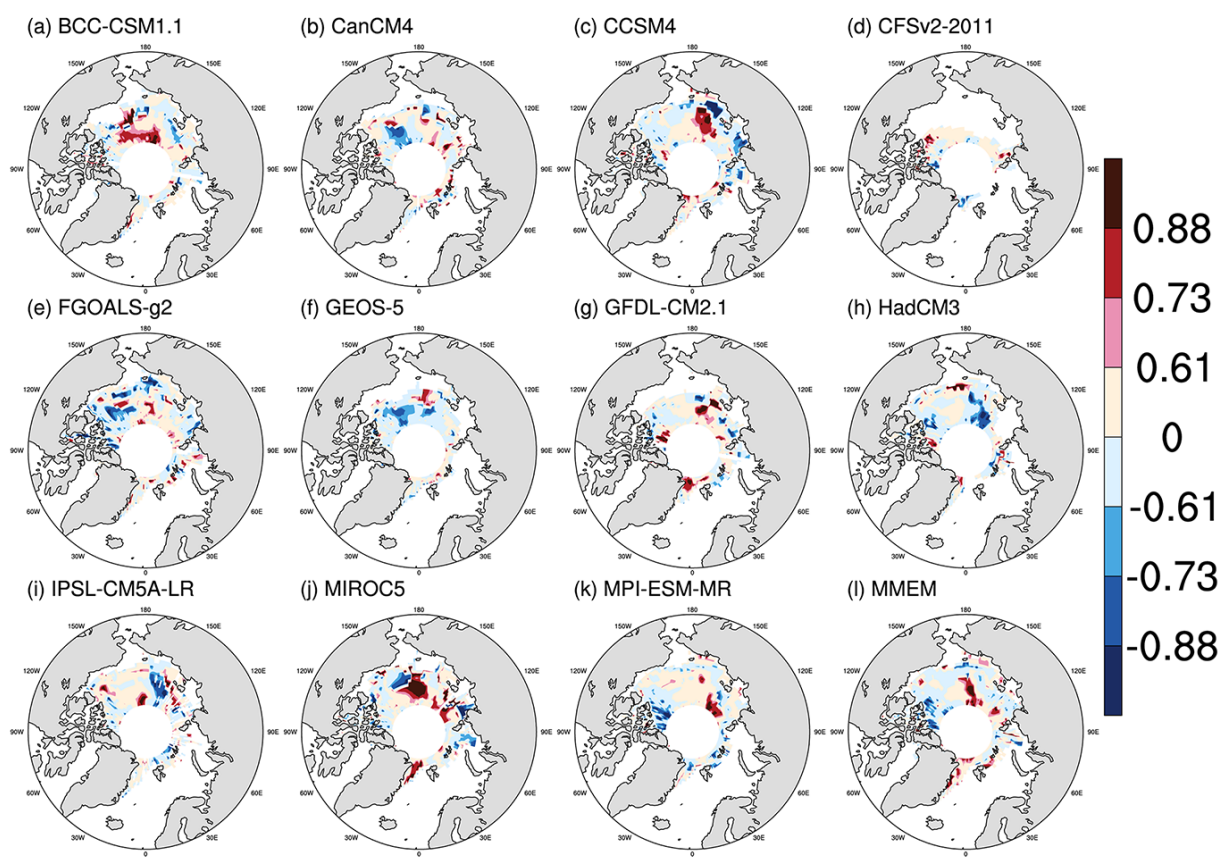

Figure 5. Same as Fig. 3, but for detrended September sea ice concentration anomalies.

Persistence prediction is the simplest way to produce a forecast, which assumes sea ice state at the time of the forecast will not change (that is the predicted sea ice extent for all lead time equals the ice extent at lead time 0 ). The horizontal lines in Fig. 6 represent different confidence levels. For the entire Arctic (Fig. 6a), the anomaly correlation coefficient of most models exhibits certain predictive skill (>95\% significance), except BCC-CSM1.1 for the lead time of 1-3 and 2-4 years. Four models (CCSM4, FGOALS-g2, GFDLCM2.1, and MIROC5) show comparable or better predictive 

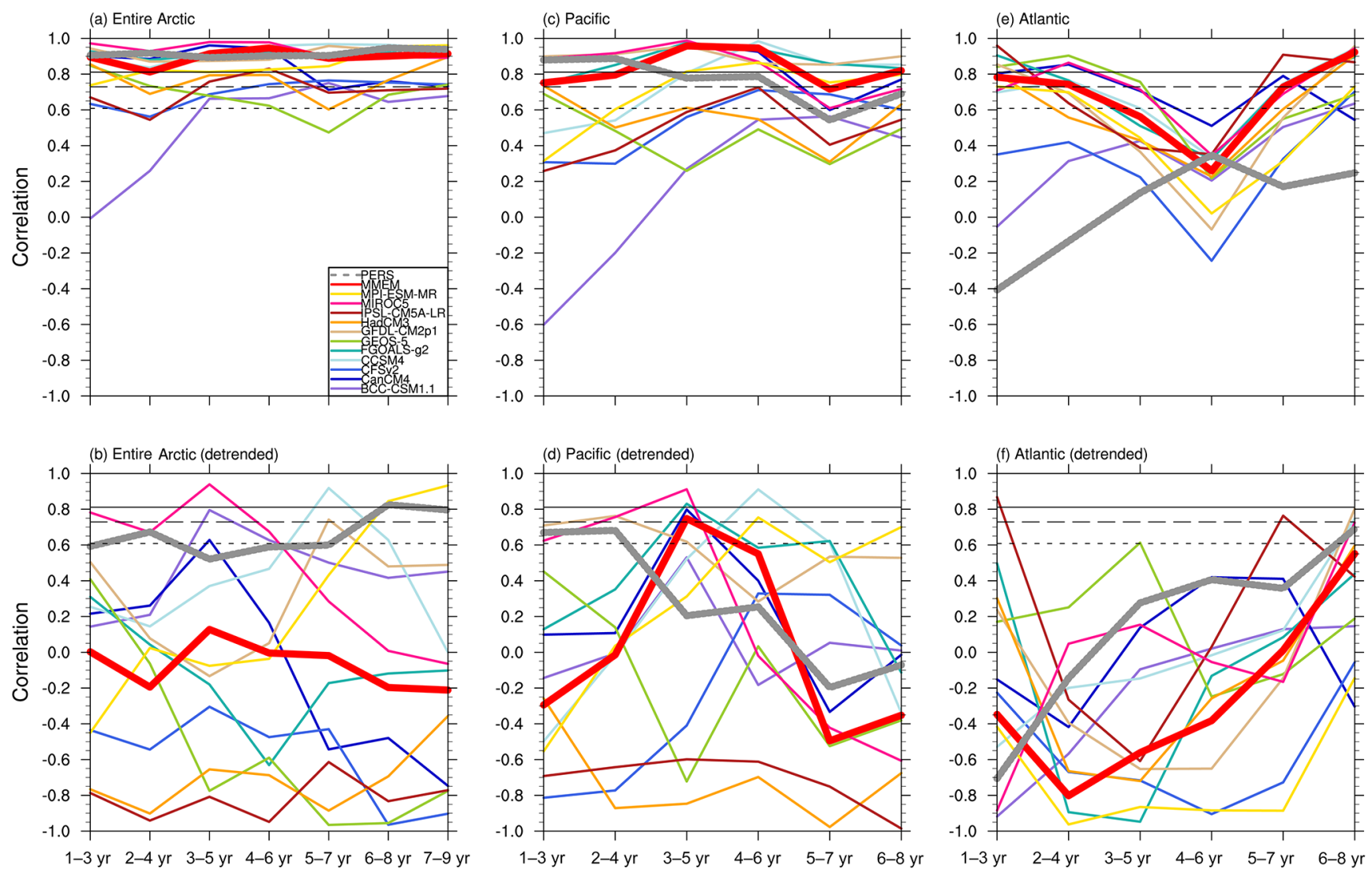

Figure 6. Anomaly correlation coefficients between the simulated and observed Arctic September sea ice extent anomalies for the three regional indices (the entire Arctic, Pacific, and Atlantic) as a function of the lead time. The top and bottom panels are the original and detrended time series, respectively. The horizontal dashed and solid lines represent 90, 95, and $99 \%$ confidence levels. The thick gray line is the persistence prediction.

skill relative to the persistence prediction for all the analyzed lead times. The MMEM has more skillful results than most of the individual model predictions during the entire period. The North Pacific sea ice index has lower prediction skill and larger inter-model spread compared to those of the entire Arctic index (Fig. 6c). In the North Pacific, only two models (GFDL-CM2.1 and MIROC5) show comparable skill to the persistence prediction for the lead time of $1-3$ and 2-4 years. After 3-5 years, six models (CanCM4, CCSM4, FGOALSg2, GFDL-CM2.1, MIROC5, and MPI-ESM-MR) have better skill than the persistence prediction, which is also the case for the MMEM. In general, the predictive skill of the North Atlantic sea ice index is poor compared to both the entire Arctic and North Pacific indices, particularly for the lead time from 3-5 to 5-7 years (insignificant ACCs). However, we note that in the North Atlantic sector all the models show better predictive skill than the persistence prediction for the first three lead times. Additionally, all the models, except CanCM4, appear to have a re-emerging predictive skill for sea ice in the North Atlantic after 6-8 years (Fig. 6e). This might be associated with the influence of the Atlantic
Meridional Overturning Circulation (AMOC; see Sect. 4 for details). Overall, the MMEM has more skillful results than that of the persistence prediction.

After removing the linear trend (Fig. 6b, d, f), the predictive skill of the above indices decreases dramatically with very large inter-model spread. The MMEM only shows more skillful results than the persistence prediction between 3-5 and 5-7 years for the North Pacific index.

\subsection{Antarctic sea ice}

Here we apply the same analysis in Sect. 3.1 for Antarctic sea ice. Figure 7 shows the time series of September sea ice extent from the 10-year hindcast for each individual model and the observations during 1981-2015. FGOALS-g2, GEOS-5, and MIROC5 produce significantly less sea ice compared to the observation for the entire period with GEOS-5, which has the smallest sea ice extent of all the models. BCCCSM1.1, CanCM4, and HadCM3 produce more sea ice relative to the observations. The sea ice extent simulated by CCSM4, CFSv2, GFDL-CM2.1, IPSL-CM5A-LR, and MPIESM-MR is comparable to the observations, but they cannot 

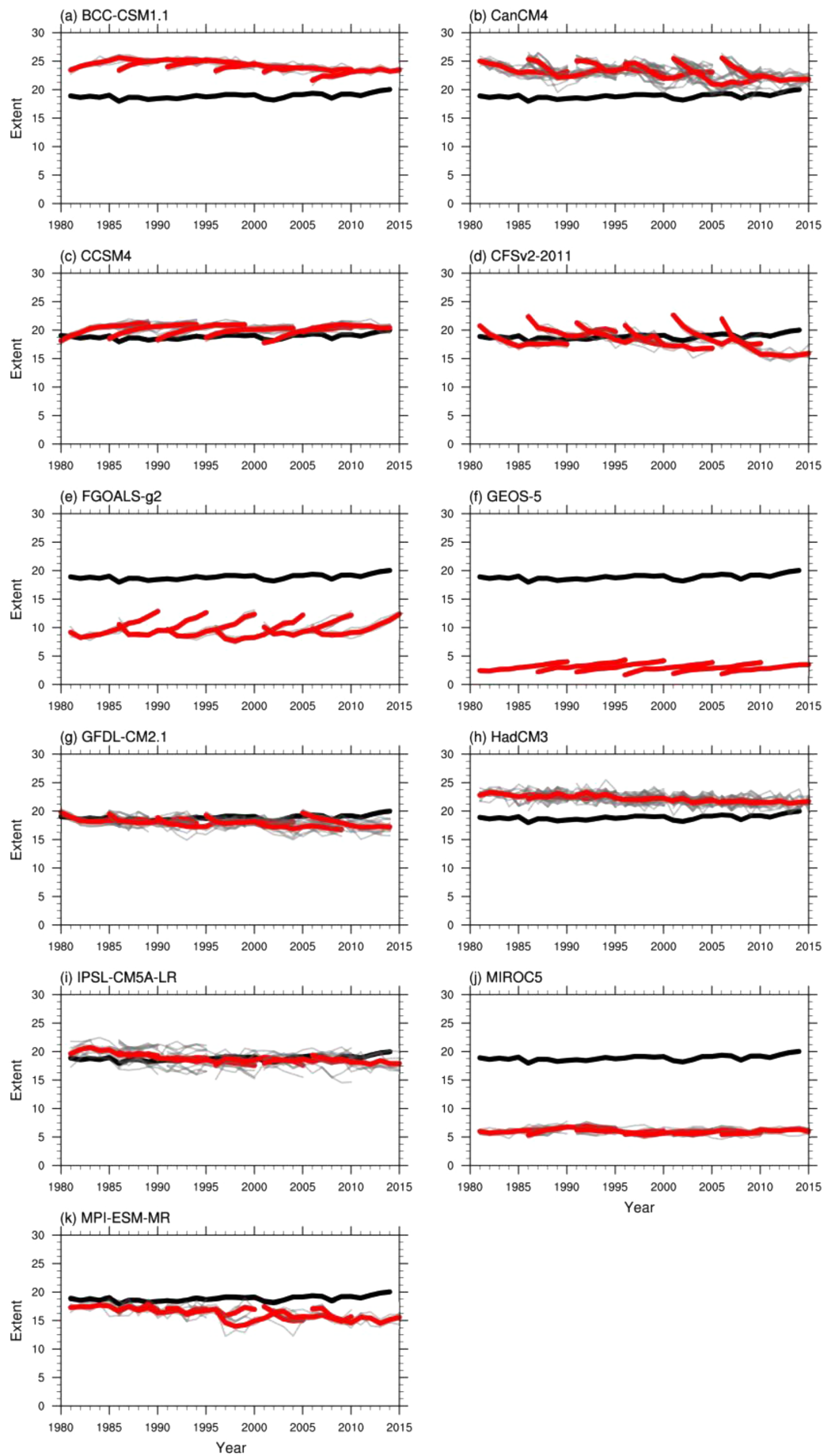

Figure 7. Time series of September Antarctic sea ice extent (seasonal minimum) from the simulations of the 10-year hindcast for each ensemble member of each individual model (thin gray line), the ensemble mean of each individual model (thick red line), and satellite observation (black line) from 1981 to 2015.

reproduce the gradual increase of Antarctic sea ice in recent years (e.g., Comiso et al., 2011). As in the Arctic, the models that use direct and indirect full-field initialization tend to drift towards their modeled sea ice state within a few years of initialization.
Figure 8 shows the anomaly correlation coefficient of each individual model and MMEM for the lead time of 1 and 3-5 years. For the 1-year lead time, small scattered areas with predictive skill greater than $95 \%$ confidence level in the Southern Ocean are found in most models. The location of 
1 year
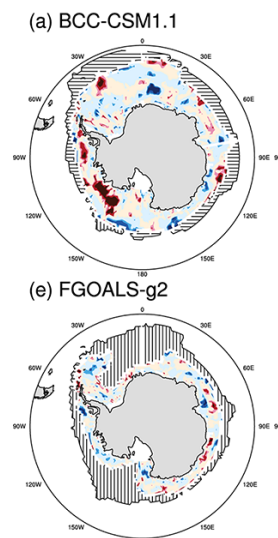

(i) IPSL-CM5A-LR (b) CanCM4

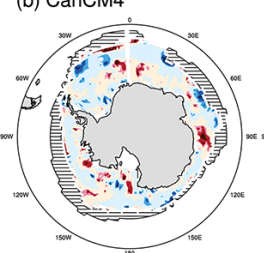

(f) GEOS-5 (c) CCSM4

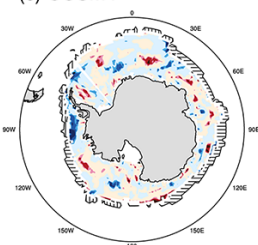

(g) GFDL-CM๊2.1

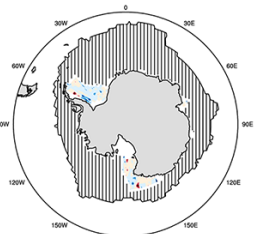

(j) MIROC5

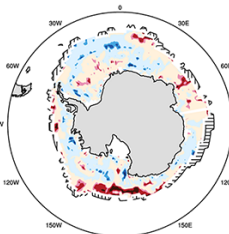

(k) MPI-ESM-MR
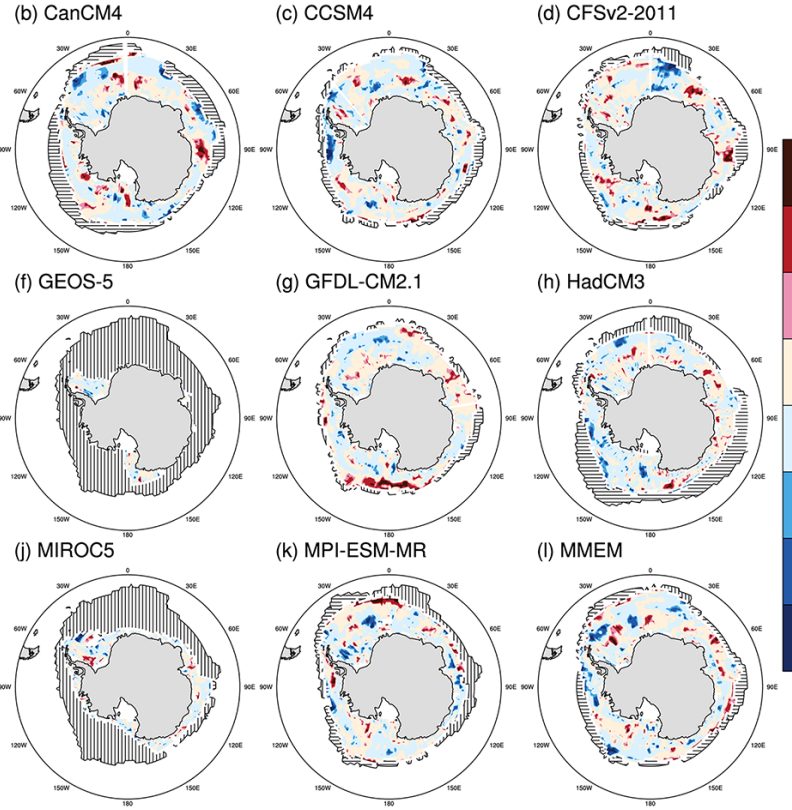

(h) $\operatorname{HadCM} 3$

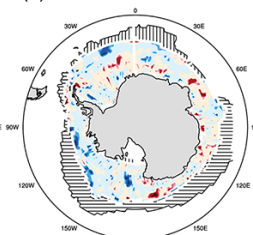

(l) MMEM

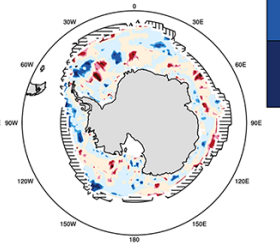

$-0.73$

$-0.88$

3-5 years

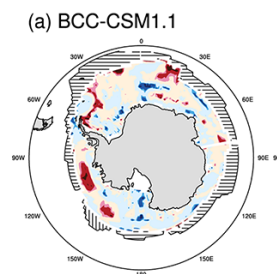

(e) FGOALS-g2

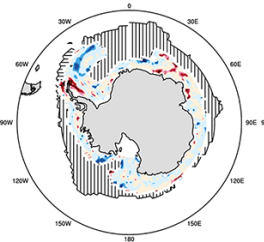

(i) IPSL-CM5A-LR

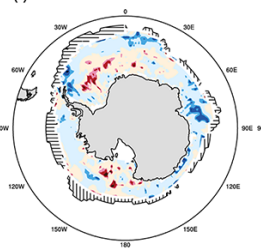

(b) CanCM4

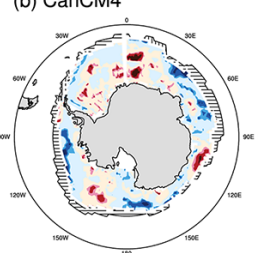

(f) GEOS-5 (c) CCSM4

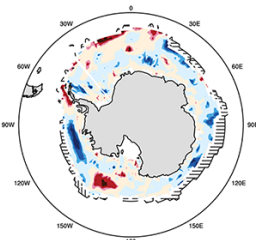

(g) GFDL-CM2.1

(d) CFSv2-2011

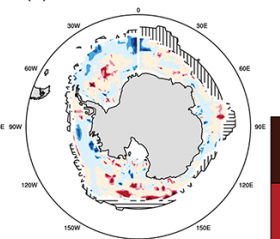

(h) $\mathrm{HadCM} 3$

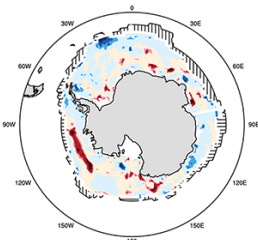

(k) MPI-ESM-MR

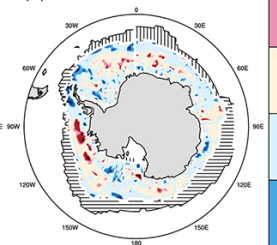

(I) MMEM
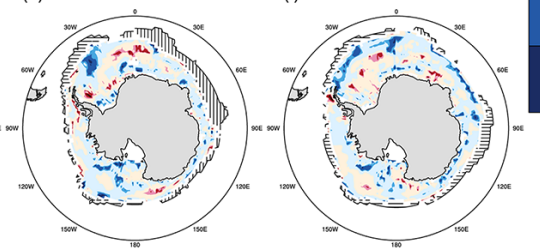

0.88

0.73

0.61

0

$-0.61$

$-0.73$

$-0.88$

Figure 8. Anomaly correlation coefficients between the simulated and observed Antarctic September sea ice concentration anomalies for the lead time of 1 year (top panel) and 3-5 years (bottom panel). The correlation coefficients of $0.61,0.73$, and 0.88 represent 90,95 , and $99 \%$ confidence levels, respectively. Horizontal lines depict the areas where the model simulation has sea ice, whereas the observation does not have sea ice. The opposite is the case for vertical lines.

these scattered areas differs by model, although the MMEM shows small clustered areas of significant ACCs in the central Weddell Sea (top panel of Fig. 81). There is no improvement for the predictive skill for most models and the MMEM as the lead time increases to $3-5$ years (bottom panel of Fig. 8) and 6-8 years (not shown). Overall, the predictive skill of the MMEM does not outperform most models for all the lead times. 


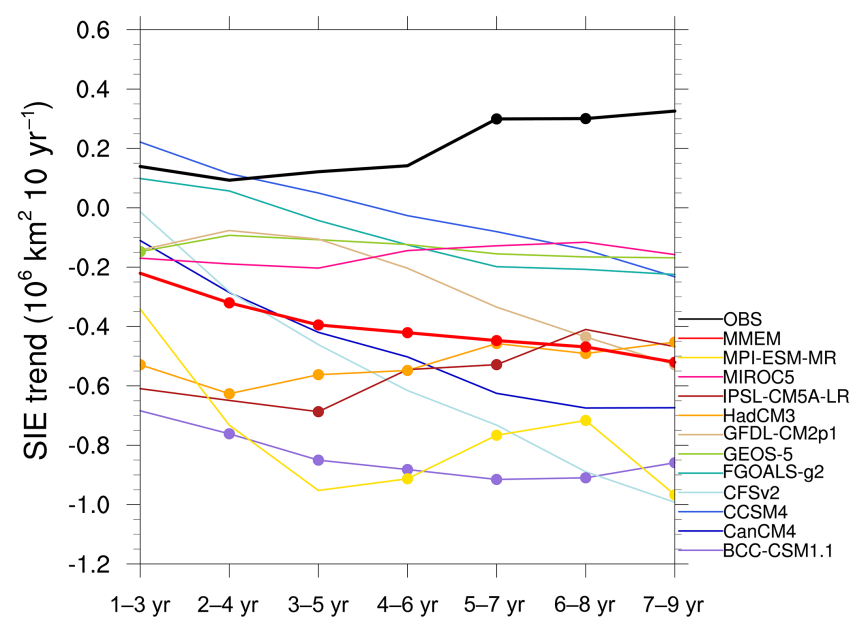

Figure 9. The predicted trends (slope of a linear regression) of September Antarctic sea ice extent (SIE) anomalies as a function of the lead time after applying a 3-year average. The dots represent the trends exceeding $95 \%$ confidence level.

The observed and predicted trends for different lead times are shown in Fig. 9. The observed trends are positive for all the lead times, and increase to $\sim 0.35 \times 10^{6} \mathrm{~km}^{2}$ per decade as recent years are considered. By contrast, most models show negative trends; i.e., BCC-CSM1.1 has negative trends ranging from $-0.6 \times 10^{6}$ to $-1 \times 10^{6} \mathrm{~km}^{2}$ per decade. CCSM4 and FGOALS-g2 have increasing trends before 3-5 and 5-7-year leads, respectively, but decreasing trends thereafter. CFSv2 shows increasing trends after 2-4-year leads. However, these three positive-trending models cannot simulate the magnitude of observed positive trends.

Again, we remove linear trends in both the model hindcast and observation, and then calculate the ACC. After the linear trend is removed, the areas with significant predictive skill become relatively broader for the majority of the models compared to those of the raw data at longer lead times; i.e., the MMEM has relatively better predictive skill in the northern Ross Sea and a large portion of the Weddell Sea at the lead time of 3-5 years (Fig. 10 vs. Fig. 8).

Here we generate three regional sea ice extent indices: (1) the entire Antarctic, (2) the central-eastern south Pacific, and (3) the south Atlantic. We define the central-eastern south Pacific index as the total September sea ice extent in the eastern Ross, Bellingshausen, and Amundsen seas (165$75^{\circ} \mathrm{W}$ and $50-80^{\circ} \mathrm{S}$ ) and the south Atlantic index as the total September sea ice extent in the Weddell Sea $\left(60-0^{\circ} \mathrm{W}\right.$ and $50-75^{\circ}$ S; see boxes in Fig. 1).

Figure 11 shows the anomaly correlation coefficient as a function of lead times for the ensemble mean of each individual model, the MMEM, and the persistence prediction. For the entire Antarctic, none of the models can predict the observed sea ice variability (i.e., their simulations are negatively correlated with the observations), except for CCSM4 and GFDL-CM2.1, which show significant prediction skill (> $95 \%$ significance) at the lead time of 1-3 years (Fig. 11a). Moreover, the persistence prediction is superior to the prediction of each individual model and the MMEM. For the central-eastern south Pacific index, almost all the models show poor predictive skill for almost all the lead times, although CFSv2, GFLD-CM2.1, and HadCM3 exhibit significant skill at 1-3,2-4, and 4-6 years, respectively. Unlike the entire Antarctic, the MMEM of the central-eastern south Pacific shows better skill than that of the persistence prediction, although neither is statistically significant (Fig. 11c). For the south Atlantic index (Fig. 11e), almost all the models also do not have predictive skill (the ACCs are not statistically significant).

After removing linear trends in Fig. 11a, c, and e, we note that there is no significant improvement in predictive skill for the regional indices, although the MMEM shows better skill than that of the persistence prediction at longer lead times, and the inter-model spread is increased (Fig. 11b, d, f).

\section{Discussion and conclusion}

This assessment provides a snapshot of the interannual to decadal predictability of sea ice in the Arctic and Antarctic for the present-day coupled global climate models as part of the CMIP5 decadal prediction experiment.

Our evaluation shows that for many models, there are substantial discrepancies between the decadal hindcast and observed September sea ice extent. By performing the anomaly correlation analysis, we found that in the Arctic, most models only show small clustered areas with significant predictive skill at the lead time of 1 year. As the lead time increases, for most models, the areas with significant predictive skill expand, covering much of the northern Beaufort, Chukchi, eastern Siberian, and Laptev seas. Such expansion is largely due to the fact that almost all the models can predict observed negative trends of Arctic sea ice, although the magnitude of the trend simulated by most models is still smaller than observed. After the linear trend is removed, the areas with significant predictive skill at longer timescales shrink greatly. We further repeated the analysis for March Arctic sea ice (not shown). It appears that all the models only show scattered areas with significant predictive skill at the lead time of 1 year, and no obvious expansion of areas with significant predictive skill is found as the lead time increases. After the trend is removed, there is not much change in the areas with significant predictive skill compared to those of the raw data. This is partly due to the fact that the observed and simulated March sea ice extent trends are small.

The analysis of regional indices suggests that sea ice in the Atlantic side has lower predictability than that of the Pacific side. This is perhaps counterintuitive since the AMO is well predicted compared to the PDO (Kim et al., 2012). We note that, for the Atlantic side of the Arctic, most mod- 
1 year
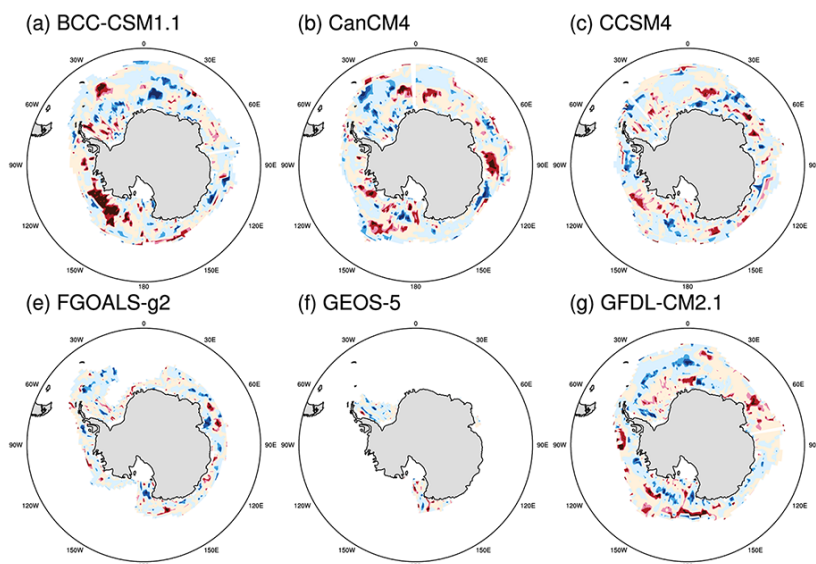

(f) GEOS-5

(g) GFDL-CM2.1

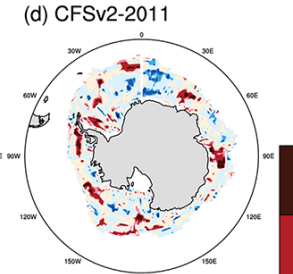

0.88
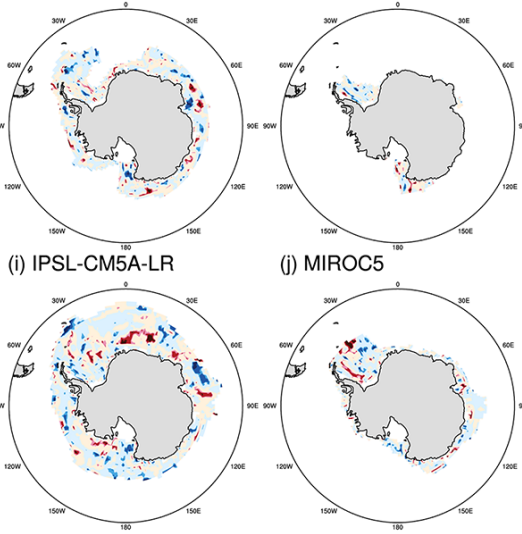

(j) MIROC5

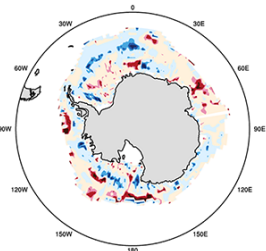

(h) $\mathrm{HadCM} 3$

0.73

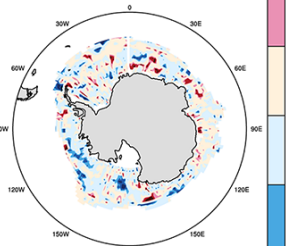

0.61

0

$-0.61$
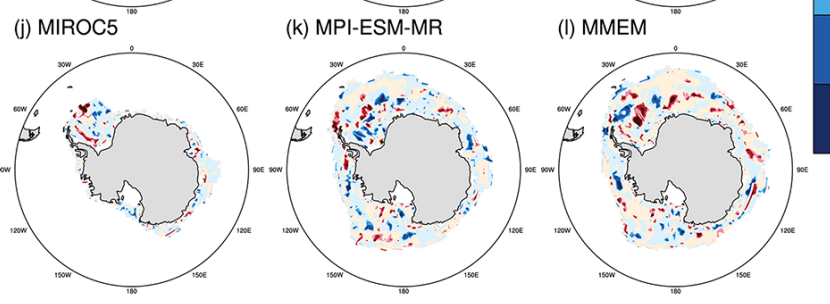

$-0.73$

\section{$3-5$ years}
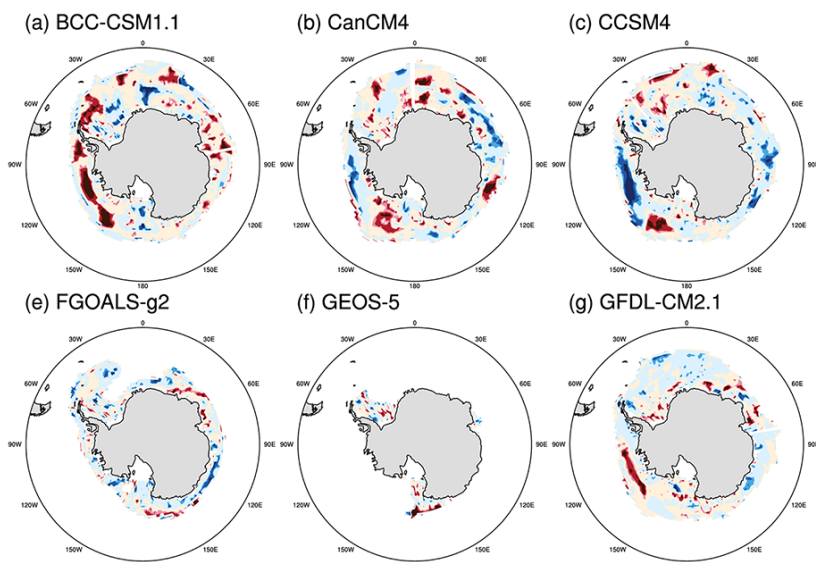

(f) GEOS-5

(g) GFDL-CM2.1

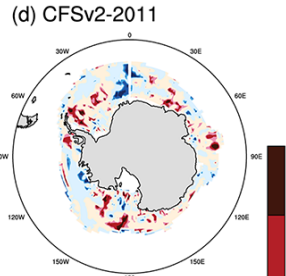

0.88
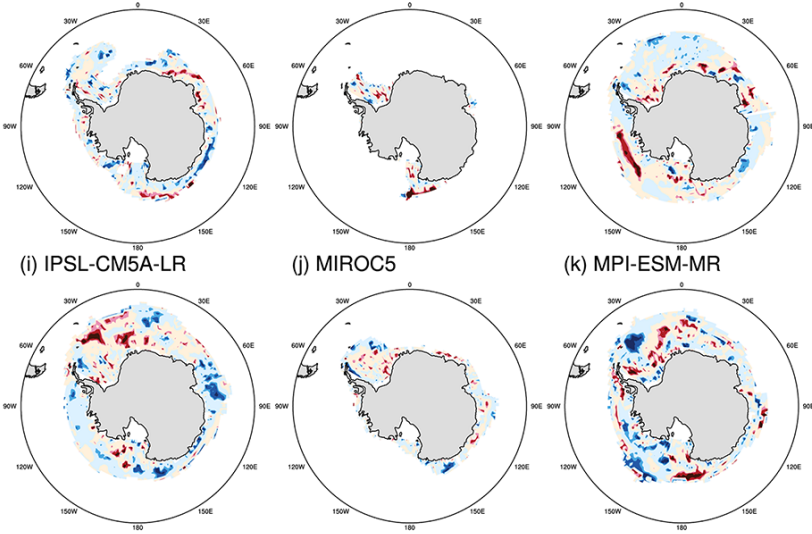

(j) MIROC5

(h) $\mathrm{HadCM} 3$

0.73

$-0.88$

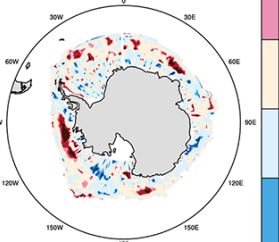

0.61

0

$-0.61$

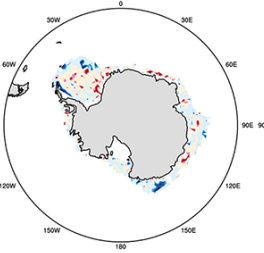

(k) MPI-ESM-MR

(I) MMEM
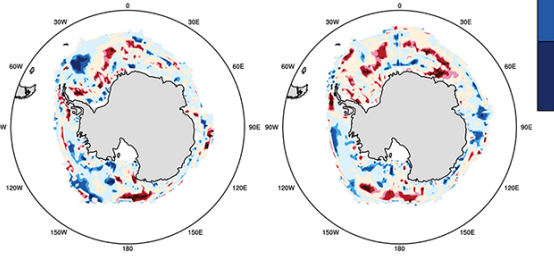

$-0.88$

Figure 10. Same as Fig. 8, but for detrended September sea ice concentration anomalies.

els show re-emerging predictive skill at the lead time of 68 years. This might be associated with the existence of interior Atlantic Meridional Overturning Circulation (AMOC) pathways. A stronger (weaker) AMOC results in warming (cooling) in the subpolar gyre after several years, contribut- ing to enhanced decadal predictability of sea ice in the North Atlantic sector (e.g., Mahajan et al., 2011; Zhang and Zhang, 2015). In contrast to September, the analysis of March regional indices suggests that sea ice in the Atlantic side has higher predictability than that of the Pacific side. Some ide- 

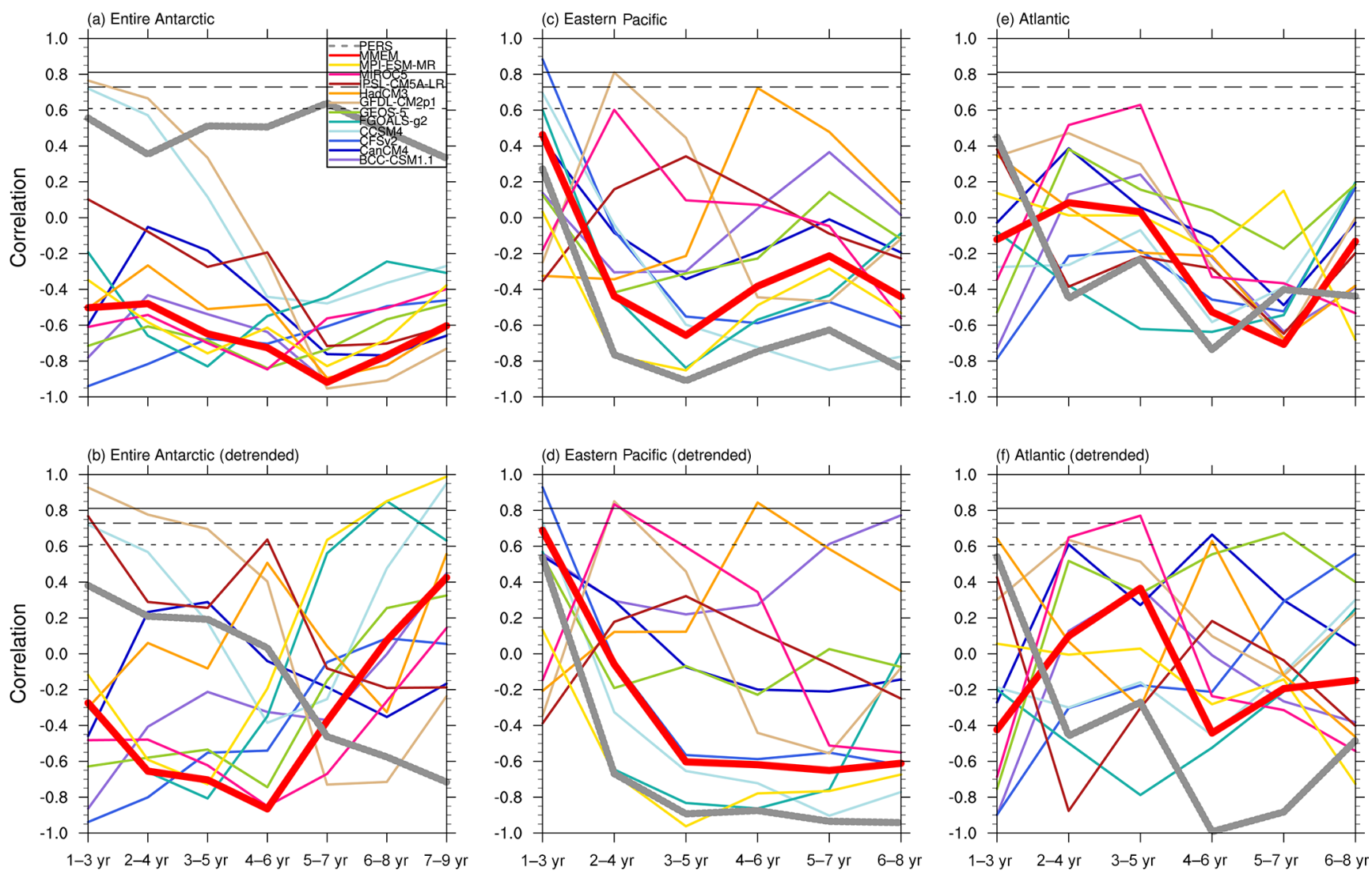

Figure 11. Anomaly correlation coefficients between the simulated and observed Antarctic September sea ice extent anomalies for the three regional indices (the entire Antarctic, eastern Pacific, and Atlantic) as a function of the lead time. The top and bottom panels are the original and detrended time series, respectively. The horizontal dashed and solid lines represent 90, 95, and 99\% confidence levels. The thick gray line is the persistence prediction.

alized modeling studies (Koenigk and Mikolakewicz, 2009; Koenigk et al., 2012), which assess predictive skills relative to their model climate, suggested that annual and decadal mean sea ice concentration has higher potential predictability for the Atlantic side than that of the Pacific side. Germe et al. (2014) showed that the potential predictability of the winter Arctic sea ice extent comes mainly from the Atlantic sector, while the Pacific sector seems unpredictable beyond the first year. Zhang (2015) suggested that it is important to monitor internal variability associated with the heat transport into the Arctic from the Atlantic and Pacific, and the Arctic dipole for predicting September Arctic sea ice extent variations. This study also pointed out all these processes are important for low-frequency variability of summer sea ice extent, while the Atlantic heat transport might be the prime driver for winter Arctic sea ice extent variability at low frequency.

By contrast, Antarctic sea ice does not show promising predictive skills at longer timescales. Unlike its Arctic counterpart, there is minimal change in the areas showing significant predictive skill as the lead time increases. One possibil- ity for the lack of predictive skill for Antarctic sea ice might be that all the models were initialized on 1 January, except CFSv2 and HadCM3 (see Table 1) since the low Antarctic sea ice cover (confined to coastal Antarctica) of 1 January translates into little persistence, and little sea ice "information". Although CFSv2 and HadCM3 were initialized on 1 November, at a time of larger Antarctic sea ice cover, they do not show better predictability than the models initialized on 1 January. This suggests another possible explanation for the lack of predictive skill: most models cannot predict the observed increasing Antarctic sea ice in recent decades. Instead, almost all decadal hindcasts predict a decrease of Antarctic sea ice, which is also true for the simulations in recent decades that include increased greenhouse gases in the atmosphere (e.g., Liu and Curry, 2010; Turner et al., 2013; Shu et al., 2015). The reasons behind the recent increase of Antarctic sea ice are complex, and several recent studies show that scientists are still trying to understand it. The possible mechanisms include variations in atmospheric circulation linked to the Antarctic Oscillation, Amundsen Sea low pressure system, stratospheric ozone depletion, and in- 

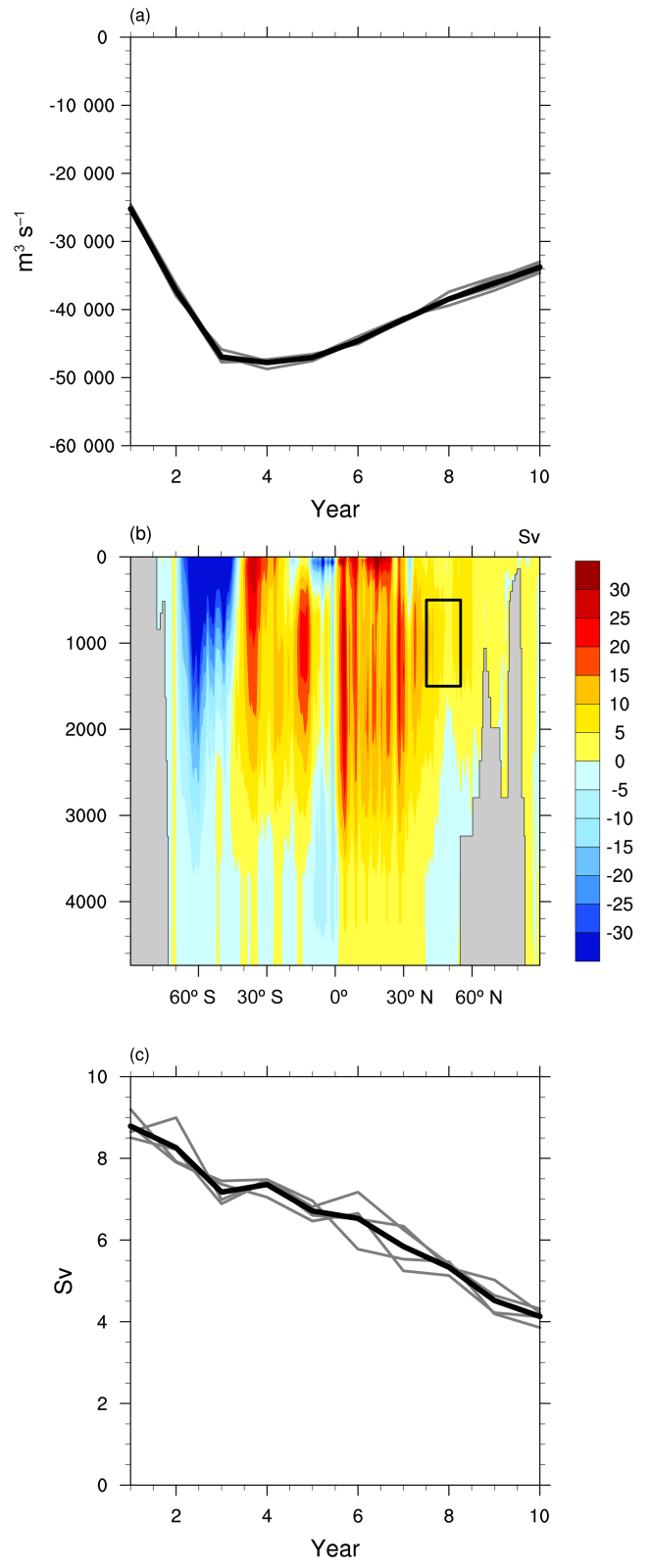

Figure 12. (a) Freshwater export through the Fram Strait (the cross section along $74^{\circ} \mathrm{N}$ and between $30^{\circ} \mathrm{W}$ and $10^{\circ} \mathrm{E}$ ), (b) Atlantic Ocean Meridional Overturning stream function in September averaged for all decadal hindcasts from 1981 to 2015 for the CFSv2 and (c) time series of stream function averaged over $40-55^{\circ} \mathrm{N}, 500$ $1500 \mathrm{~m}$ as indicated by the black box in the middle panel. The thin gray line represents each ensemble member, and the thick black line represents the ensemble mean.

creased greenhouse gases, changes in zonal and meridional near-surface winds, the increase in freshwater flux that stabilizes the upper ocean layer, and the influence of internal variability (e.g., Zhang, 2007; Turner et al., 2009; Sigmond and Fyfe, 2010; Liu and Curry, 2010; Holland and Kwok, 2012; Zunz et al., 2013; Polvani and Smith, 2013). How-
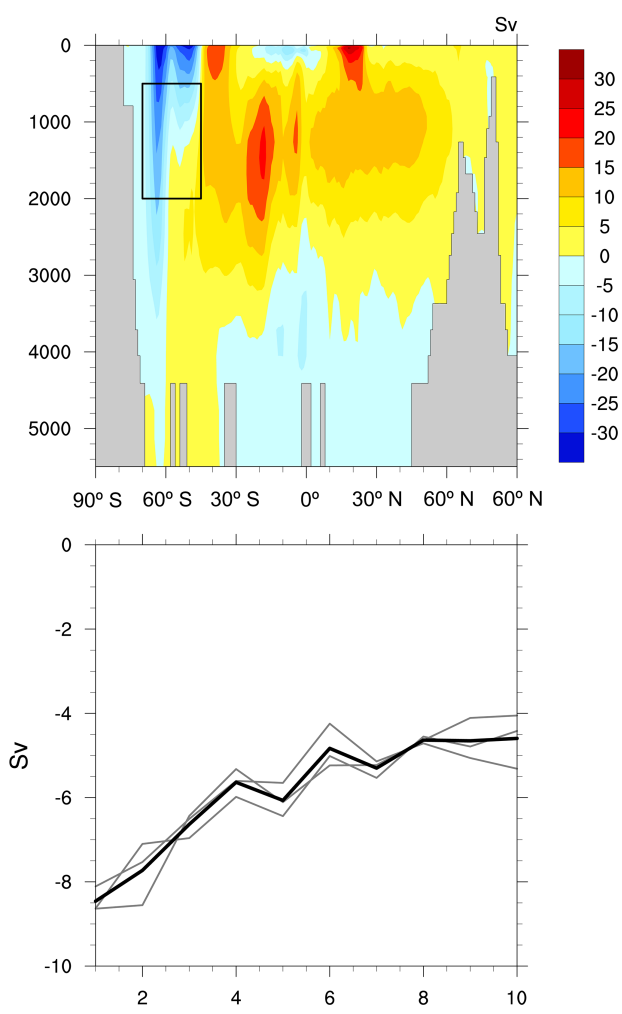

Figure 13. Atlantic Ocean Meridional Overturning stream function in September averaged for all decadal hindcasts from 1981 to 2015 for GEOS-5 (upper panel) and time series of stream function averaged over $45-70^{\circ} \mathrm{N}, 500-2000 \mathrm{~m}$ as indicated by the black box in the upper panel (lower panel). The thin gray line represents each ensemble member, and the thick black line represents the ensemble mean.

ever, it is not clear which is the dominant process. Further investigating a range of other variables such as simulated sea ice thickness, sea ice velocity, near-surface wind, and ocean stratification will help elucidate the reasons why the trends in these models are different from observations. However, after the trend is removed, most models suggest relatively better predictive skill in the northern Ross Sea and a large portion of the Weddell Sea. Previous studies (e.g., Liu et al., 2002) have shown that the intensification of the Hadley circulation in the eastern equatorial Pacific during El Niño leads to an equatorward shift of the storm track in the Ross Sea. This leads to changes in the regional Ferrel circulation in the Ross Sea, which cause an anomalous poleward mean meridional heat flux into the sea ice zone in the Ross Sea and limit sea ice growth. The opposite is the case for the Weddell Sea. Thus, relatively better sea ice predictability in the northern Ross Sea and a large portion of the Weddell Sea might be related to the El Niño-Southern Oscillation (ENSO) teleconnection. Holland and Raphael (2006) have further shown that a number of climate models have the ability to simulate the observed ENSO teleconnection in sea ice in the eastern south 
1 year
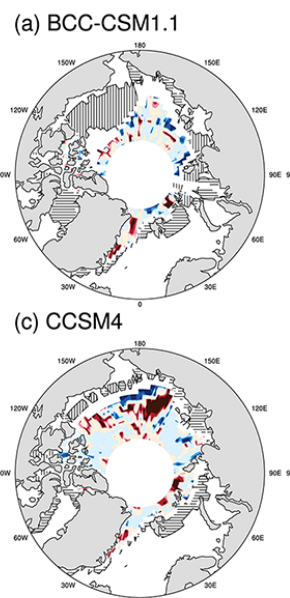

(e) GFDL-CḾ2.1

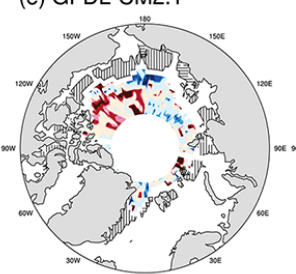

(g) IPSL-CM5A-LR

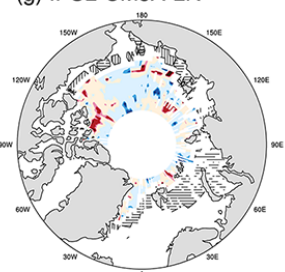

(i) MPI-ESM-MR

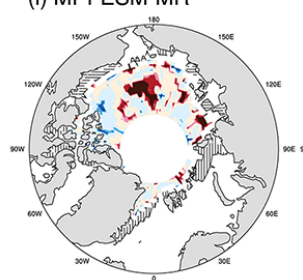

(b) $\mathrm{CanCM} 4$

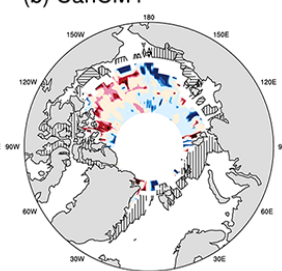

(d) FGOALS-g2

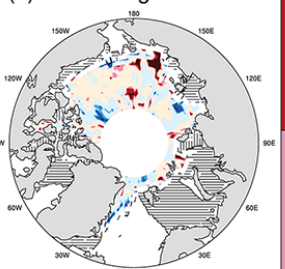

(f) $\mathrm{HadCM} 3$

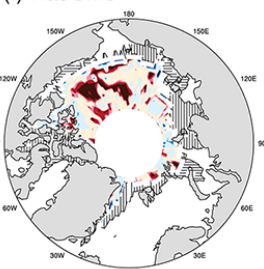

(h) MIROC5

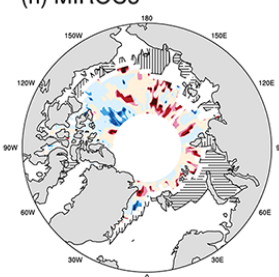

(j) MMEM

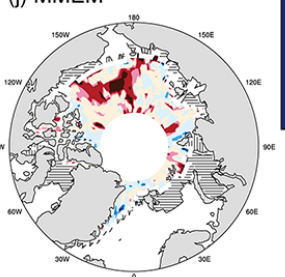

0.88

0.73

0.61

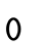

$-0.61$

$-0.73$

$-0.88$
$3-5$ years

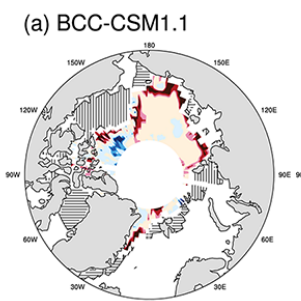

(c) CCSM 4

(b) $\mathrm{CanCM} 4$

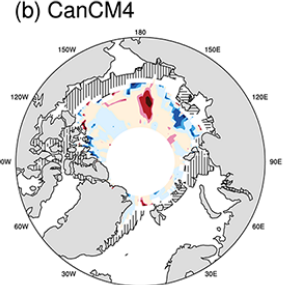

(d) FGOALS-g2

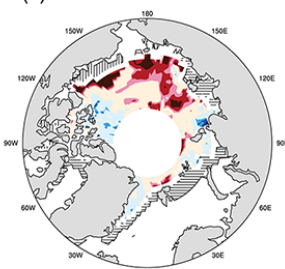

(e) GFDL-CM⒉1

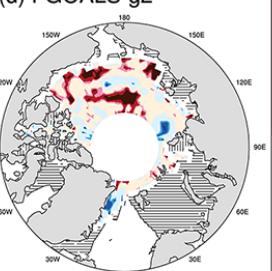

0.88

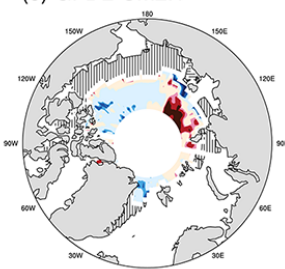

(g) IPSL-CM5A-LR

(f) $\mathrm{HadCM} 3$

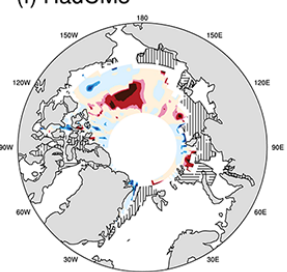

0.61

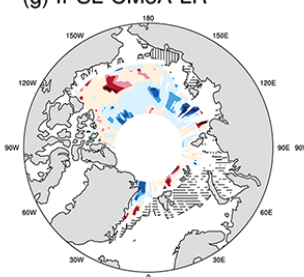

(i) MPI-ESM-MR

(h) MIROC5

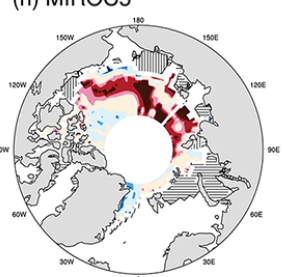

$-0.61$

$-0.73$

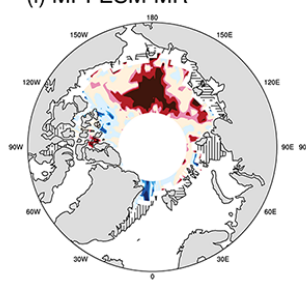

0.73

0

(j) MMEM

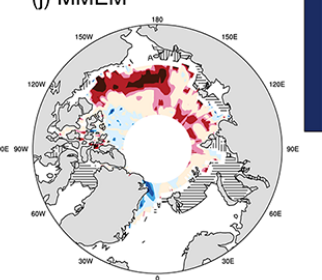

Figure 14. Anomaly correlation coefficients between the simulated and observed Arctic September sea ice concentration anomalies for the lead time of 1 year (left panel) and 3-5 years (right panel). The correlation coefficients of $0.61,0.73$, and 0.88 represent 90,95 , and 99\% confidence levels, respectively. Horizontal lines depict the areas where the model simulation has sea ice, whereas the observation does not have sea ice. The opposite is the case for vertical lines.

Pacific and Atlantic. The analysis of regional indices also shows little predictive skill for Antarctic sea ice.

As mentioned earlier, some models tend to drift away quickly from the initialized state. Here we use the biascorrection method mentioned in Ham et al. (2014) to remove the drift. This method removes the lead-time-dependent mean bias based on the observation. The bias-corrected decadal hindcast is calculated as

$\hat{Y_{j t}}=Y_{j t}-\sum_{k=1}^{N}\left(Y_{k t}-O_{k t}\right) / N$ where $Y_{j t}$ and $\hat{Y}_{j t}$ are the raw and bias-corrected predicted sea ice state, at the initialized year $j$ and lead year $t . O_{j t}$ is the observed sea ice state. We also apply this method to re-calculate the anomaly correlation coefficient between the observed and bias-corrected simulated regional sea ice indices for the Arctic and Antarctic. The results for the biascorrected decadal hindcasts are similar to those with the systematic model drift (not shown). This is because the bias correction only minimally influences the variability of the time series as reflected by the anomaly correlation coefficient. 
1 year

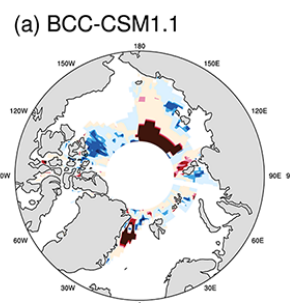

(c) CCSM4

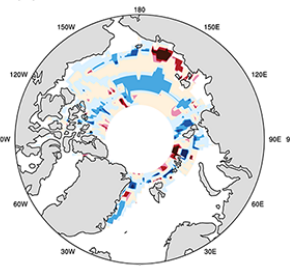

(e) GFDL-CM‥1

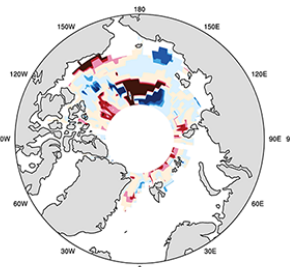

(g) IPSL-CM5A-LR

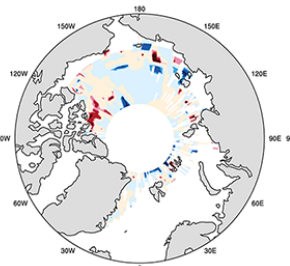

(i) MPI-ESM-MR

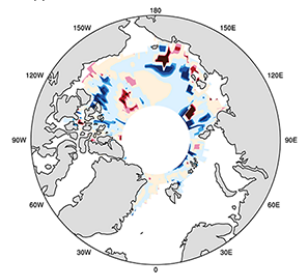

(b) $\mathrm{CanCM} 4$

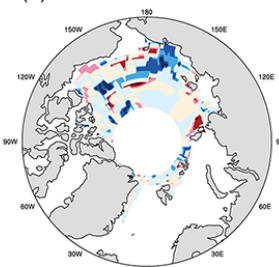

(d) FGOALS-g2

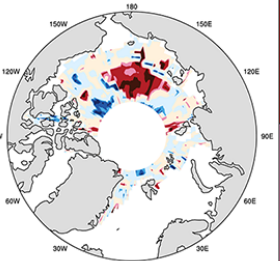

(f) $\mathrm{HadCM} 3$

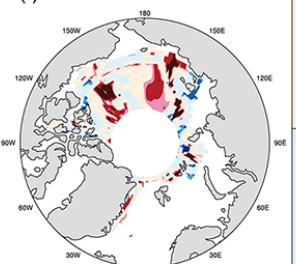

(h) MIROC5

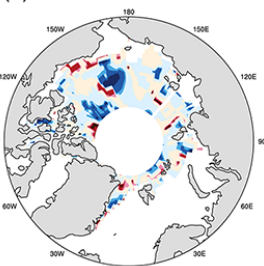

(j) MMEM

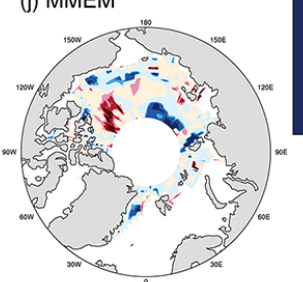

0.88

0.73

0.61

0

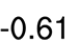

$-0.61$

$-0.73$

$-0.88$
$3-5$ years
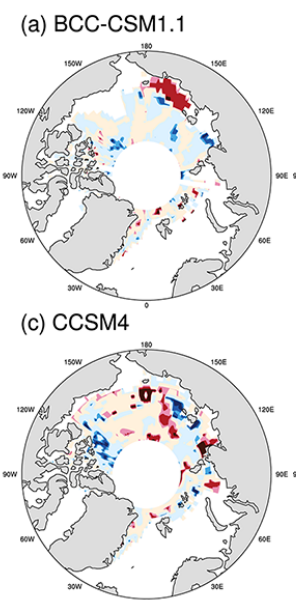

(e) GFDL-CM⒉1

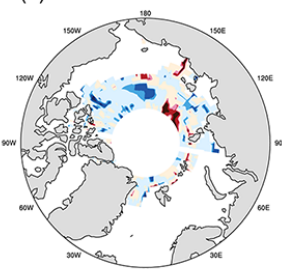

(g) IPSL-CM5A-LR

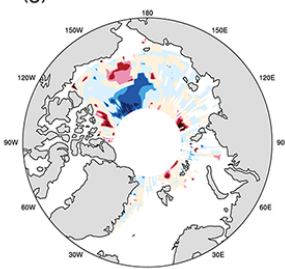

(i) MPI-ESM-MR

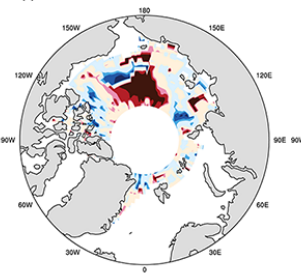

(b) $\mathrm{CanCM} 4$

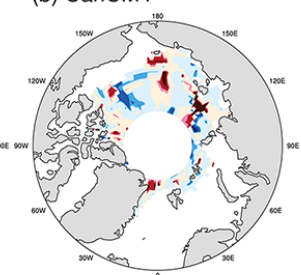

(d) FGOALS-g2

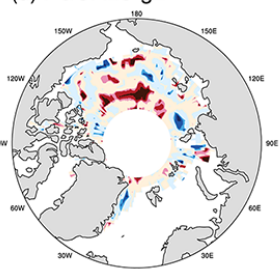

(f) $\mathrm{HadCM} 3$

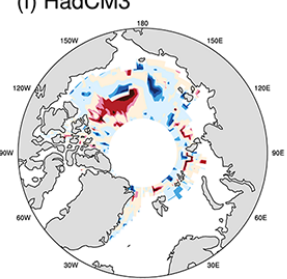

(h) MIROC5

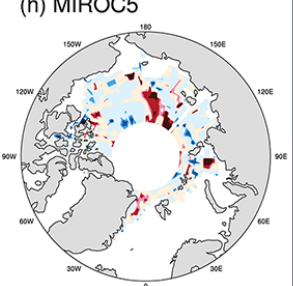

(j) MMEM

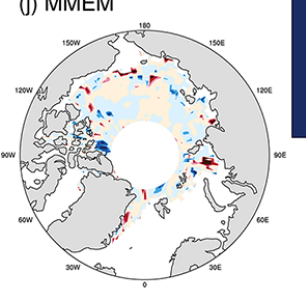

0.88

0.73

0.61

0

$-0.61$

$-0.73$

$-0.88$

Figure 15. Same as Fig. 14 but for detrended September sea ice concentration anomalies.

Continued efforts are needed to identify, understand, and reduce model errors; i.e., Kharin et al. (2012) demonstrated a technique to correct nonlinear drifts in decadal hindcasts. Some multi-model studies have put effort in the investigation of this issue for some climate variables (e.g., Bellucci et al., 2015; Doblas-Reyes et al., 2013; Goddard et al., 2013).

An issue with this assessment is the relatively small sample size because of the limited number of start years of the decadal prediction experiment. To promote both the science and practice of decadal prediction, the CMIP Phase 6 recommends ensembles of 10-year hindcast/prediction for all years from 1960 to the end of the CMIP6 period (10 members recommended), which will be helpful to obtain better statistics.
In our analysis, we note that CFSv2 dramatically underestimates September sea ice cover, leading to pronounced drift in the first 3 years of the decadal hindcast. In contrast, CFSv2 simulates a larger March sea ice extent $\left(2-3 \times 10^{6} \mathrm{~km}^{2}\right.$ more than the observation, not shown). Hence there is an excessive melt of sea ice through the melting season, which is due not only to the underestimation of observed September sea ice cover, but also to the overestimation of observed March sea ice cover (March-September). Such large errors have the potential to propagate through other components of the climate system. This excessive melt greatly increases freshwater in the Arctic Ocean and the export of freshwater through the Fram Strait into the North Atlantic. Following Koenigk 
1 year

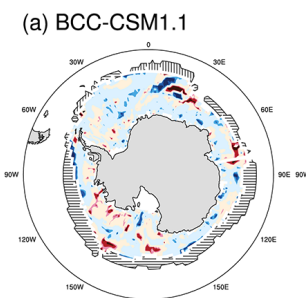

(c) CCSM4

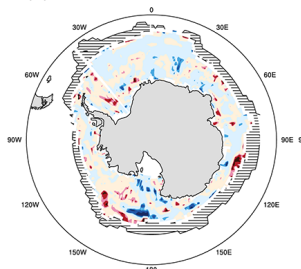

(e) GFDL-CM2.1

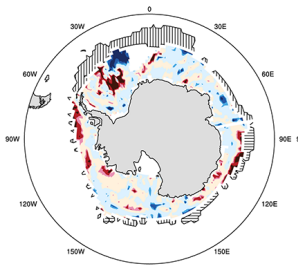

(g) IPSL-CM5A-LR

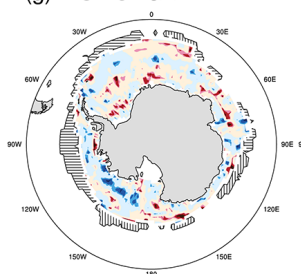

(i) MPI-ESM-MR

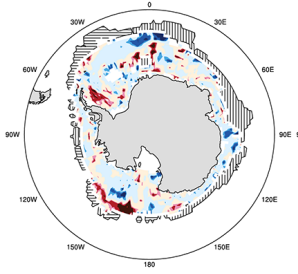

(b) $\mathrm{CanCM} 4$

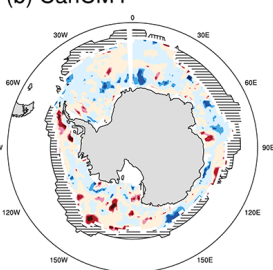

(d) FGOALS-g2

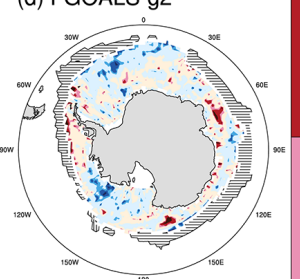

(f) $\mathrm{HadCM}{ }^{19}$

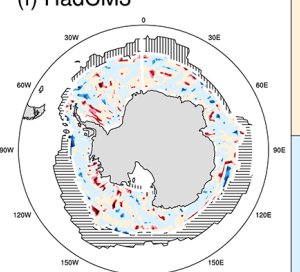

(h) MIROC5

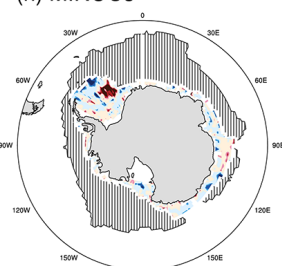

(j) MMEM

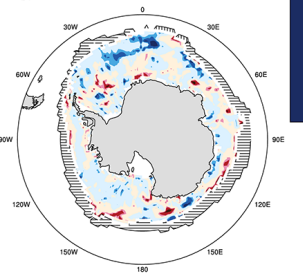

0.88

0.73

0.61

0

$-0.61$

$-0.73$

$-0.88$
3-5 years

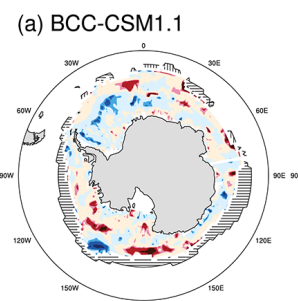

(c) $\mathrm{CCSM} 4$

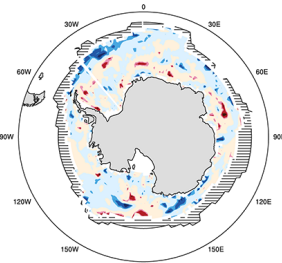

(e) GFDL-CM2.1

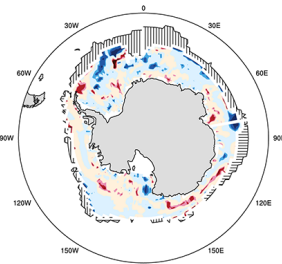

(g) IPSL-CM5A-LR

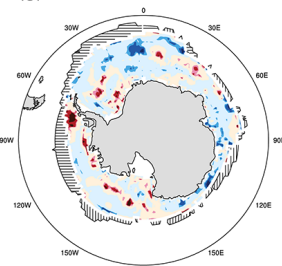

(i) MPI-ESM-MR

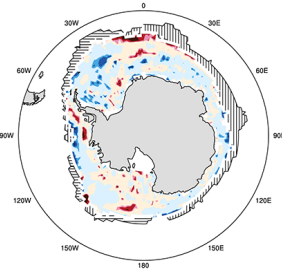

(b) CanCM4

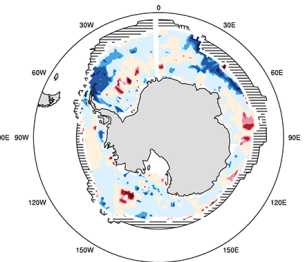

(d) FGOALS-g2

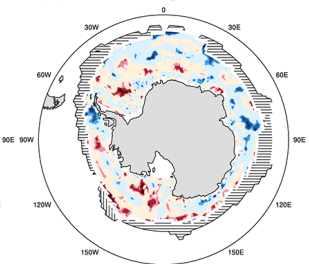

(f) $\mathrm{HadCM} 3$
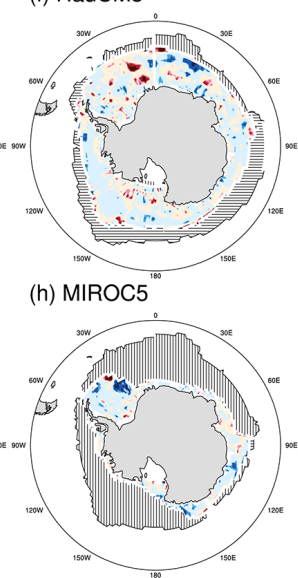

(j) MMEM

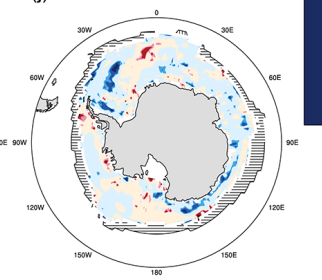

0.61

0.88

0.73

0

$-0.61$

$-0.73$

$-0.88$

Figure 16. Anomaly correlation coefficients between the simulated and observed Antarctic September sea ice concentration anomalies for the lead time of 1 year (left panel) and 3-5 years (right panel). The correlation coefficients of $0.61,0.73$, and 0.88 represent 90,95 , and $99 \%$ confidence levels, respectively. Horizontal lines depict the areas where the model simulation has sea ice, whereas the observation does not have sea ice. The opposite is the case for vertical lines.

et al. (2007), we calculate the freshwater export through the Fram Strait using the following formula:

$Q=\int_{z=\mathrm{B}}^{\mathrm{T}} \int_{x=x 0}^{x 1} u\left(\frac{S_{\mathrm{ref}}-S}{S_{\mathrm{ref}}}\right) \mathrm{d} x \mathrm{~d} z$,

where $\mathrm{B}$ is the bottom of the ocean layer (here $\mathrm{B}=100 \mathrm{~m}$ ), $\mathrm{T}$ is the the top of the ocean layer; $x 0$ and $x 1$ are end points of the selected cross section (here the cross section is along $74^{\circ} \mathrm{N}$ and between $30^{\circ} \mathrm{W}$ and $10^{\circ} \mathrm{E}$ ); $S, S_{\text {ref }}$ are salinity and reference salinity ( $\left.S_{\text {ref }}=34.8 \mathrm{psu}\right)$. As shown in Fig. 12, there is a pronounced increase of the freshwater export through the Fram Strait into the North Atlantic during the first 4 years of integration, although the amount of the freshwater export decreases gradually after that. Such freshwater propagation into the North Atlantic results in a weakening of deep water formation in the Greenland Sea. Also shown in Fig. 12, the volume transport of the Atlantic Meridional Overturning Circulation (AMOC) at $40^{\circ} \mathrm{N}$ in CFSv2 (which is too weak even at the beginning of the integration) 
1 year

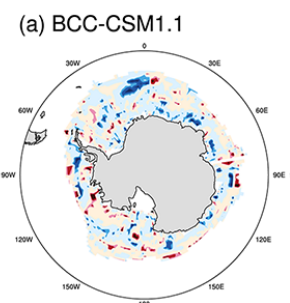

(c) CCSM4

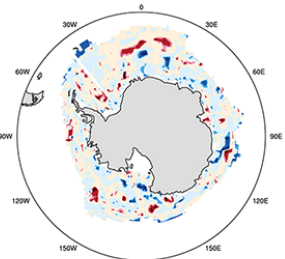

(e) GFDL-CM2.1

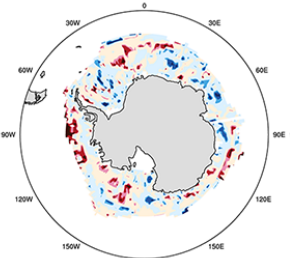

(g) IPSL-CM5A-LR

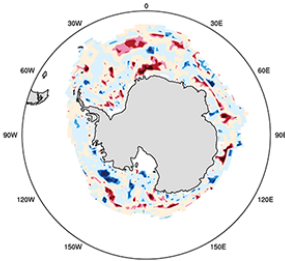

(i) MPI-ESM-MR

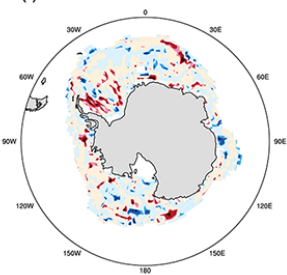

(b) $\mathrm{CanCM} 4$

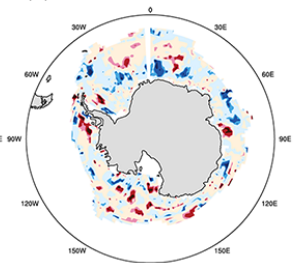

(d) FGOALS-g2

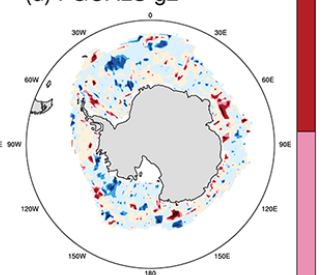

(f) $\mathrm{HadCM} 3$

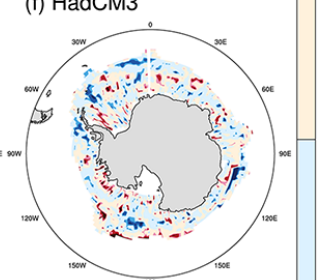

(h) MIROC5

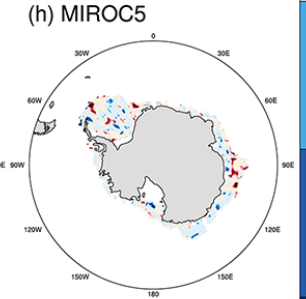

(j) MMEM

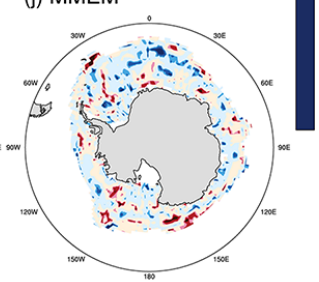

0.88

0.73

0.61

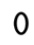

$-0.61$

$-0.73$

$-0.88$

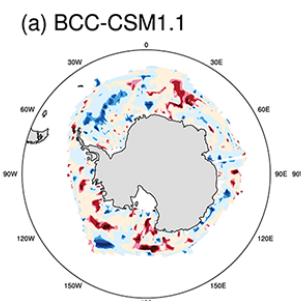

(c) CCSM4

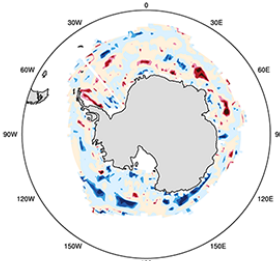

(e) GFDL-CM2.1

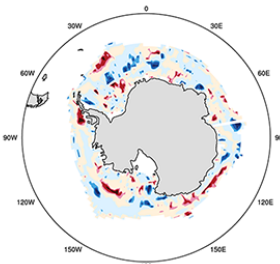

(g) IPSL-CM5A-LR

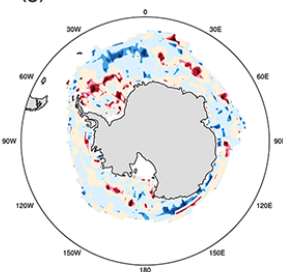

(i) MPI-ESM-MR

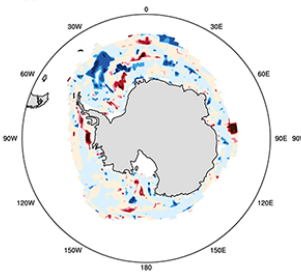

(b) $\mathrm{CanCM} 4$

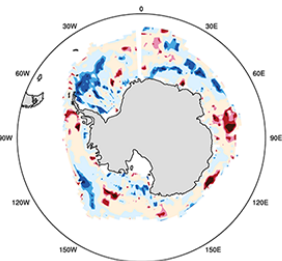

(d) FGOALS-g2
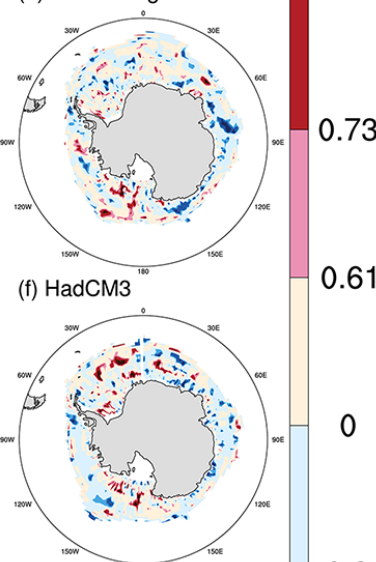

(h) MIROC5

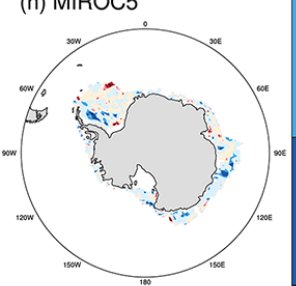

(j) MMEM

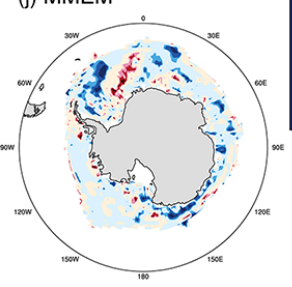

0.61

0

$-0.61$

0.88

0.73

$-0.73$

$-0.88$

Figure 17. Same as Fig. 16, but for detrended September sea ice concentration anomalies.

decreases substantially during the decadal hindcast $(4 \mathrm{~Sv}$ after 10-year integration), which is a factor of 3-4 smaller than the observation (18.7 Sv in Cunningham et al., 2007; 17.2 Sv in Smeed et al., 2014; McCarthy et al., 2015). Thus, incorrect prediction of sea ice in the Arctic could influence the AMOC prediction, which is a key source of decadal predictability for the European climate (Jackson et al., 2015), and has global impacts at longer timescales.

It is well known that brine rejection during sea ice growth strongly influences the formation of the Antarctic Bottom Water (AABW). In the Antarctic, as mentioned previously, GEOS-5 simulates much less September sea ice extent, a factor of about 6 less than the observation, which is also the case for March sea ice extent (not shown). The underestimation of sea ice coverage might result in insufficient brine rejection through the freeze-up period in the GEOS-5. This insufficient brine rejection is due not only to the underestimation of observed September sea ice cover alone, but also to the underestimation of observed March sea ice cover. Export of AABW constitutes a key component of the meridional overturning circulation in the Southern Ocean (Lumpkin and Speer, 2007). The systematic underestimation of sea ice coverage results in a weaker Deacon cell in the Southern Ocean ( $\sim 4$ Sv, Fig. 13) compared to the estimation of $20 \mathrm{~Sv}$ from Döös et al. (2008). Therefore, models that have large biases in simulating sea ice extent (e.g., CFSv2 for the Arc- 
tic, GEOS-5 for the Antarctic) result in degraded predictive skill in sea ice as well as other variables.

Recent studies have suggested that different initialization approaches and the density of observations used in the initialization significantly affect the predictability of sea ice. Zunz et al. (2015) found that the spread of ensembles at decadal timescales can be reduced when more complicated data assimilation procedures and denser observations are used to initialize the hindcasts. Here we also repeated the analysis for the historical and RCP4.5 (Representative Concentration Pathway 4.5) simulations of all the models (hereafter referred to as uninitialized simulation), except CFSv2 and GEOS-5 (they did not provide historical and RCP4.5 simulations). For the Arctic, the predictive skill of sea ice concentration is enhanced for the initialized hindcast compared to the uninitialized simulation for most models. After the trend is removed, there is no obvious difference between the initialized hindcast and the uninitialized simulation. For the Antarctic, there is not much difference between the initialized hindcast and the uninitialized simulation. However, after the linear trend is removed, the area with significant predictive skill for the initialized hindcast becomes relatively larger compared to those of the uninitialized simulation (Figs. 14-17). Note that Figs. 14 and 16 do not include CFSv2 and GEOS-5, which have poor predictive skill in the initialized hindcast. It is possible that the predictive skill of MMEM for the uninitialized simulation would be worse if CFSv2 and GEOS-5 were included.

A recent study (Chevallier et al., 2016) showed that global reanalyses that do not assimilate sea ice concentration generally overestimate sea ice concentration and have large biases near the ice edge in the Arctic. They also pointed out that none of the global reanalyses have assimilated sea ice thickness data. To date, only limited models have implemented initialization of sea ice concentration (Table 1). Based on Table 1, 11 CMIP5 models can be separated into two groups: direct and indirect sea ice initialization. The direct initialization includes CanCM4, CFSv2, GEOS-5, and HadCM3. Other models show indirect initialization. Based on this division, we cannot conclude that the models initialized directly show a better performance on predictive skills compared to those initialized indirectly. CanCM4 has a broader area with significant predictive skill at longer lead times (Fig. 3). Its predictive skill is better than some models (e.g., BCC-CSM1.1, IPSL-CM5A-LR), comparable with CCSM4 and GFDL-CM2.1, but worse than MIROC5 and MMEM. On the other hand, CFSv2 has strong model drift so that the predicted sea ice is substantially less than the observations. GEOS-5 and HadCM3 have nearly no skill in predicting observed sea ice variability. From this comparison, it is not clear whether direct sea ice initialization is better than indirect sea ice initialization. To better predict sea ice, the accurate sea ice initialization requires not only sea ice concentration, but also variables (i.e., sea ice thickness) that influence surface energy fluxes and, thereby, ocean-atmosphere interaction. At seasonal timescales, the initialization of sea ice thickness has been shown to be crucial for summer prediction (e.g., Day et al., 2014b). Some studies (e.g., Blanchard-Wrigglesworth et al., 2011a; Koenigk and Mikolajewicz, 2009) suggested that the persistence of sea ice thickness anomalies is much higher than that of sea ice concentration anomalies. Higher predictability of Arctic sea ice thickness (volume) with respect to that of Arctic sea ice cover has been found at longer timescales (e.g., Guemas et al., 2016). However, sea ice thickness has not yet been initialized in CMIP5 models because of sparse observations. Other processes important for simulating sea ice evolution include the ocean below sea ice (i.e., temperature and salinity), which, due to its long persistence time, provides constraints on predictions of sea ice at longer timescales. Thus, efforts should be devoted to further development of initialization of the Arctic Ocean and Southern Ocean, which requires sufficient observations and improved assimilation methods.

\section{Data availability}

The satellite-derived sea ice extent and concentration used in this study are obtained from the National Snow and Ice Data Center (Fetterer et al., 2016; Cavalieri et al., 1996). All model outputs used in this study are obtained from the Coupled Model Intercomparison Project Phase 5 (CMIP5), which can be downloaded from http://cmip-pcmdi.llnl.gov/cmip5/data portal.html. All results of analysis can be obtained by contacting the corresponding author.

Acknowledgements. This research is supported by the NOAA Climate Program Office (NA15OAR4310163 and NA14OAR4310216) and the NSFC (41676185).

Edited by: J. Stroeve

Reviewed by: two anonymous referees

\section{References}

Bellucci, A., Haarsma, R., Gualdi, S., Athanasiadis, P. J., Caian, M., Cassou, C., Fernandez, E., Germe, A., Jungclaus, J., Kröger, J., Matei, D., Müller, W., Pohlmann, H., Salas y Melia, D., Sanchez, E., Smith, D., Terray, L., Wyser, K., and Yang, S.: An assessment of a multi-model ensemble of decadal climate predictions, Clim. Dynam., 44, 2787-2806, doi:10.1007/s00382-014-2164-y, 2015.

Bindoff, N. L., Stott, P. A., AchutaRao, K. M., Allen, M. R., Gillett, N., Gutzler, D., Hansingo, K., Hegerl, G., Hu, Y., Jain, S., Mokhov, I. I., Overland, J., Perlwitz, J., Sebbari, R., and Zhang, X.: Detection and attribution of climate change: From global to regional, in: Climate Change 2013: The Physical Science Basis, Contribution of Working Group I to the Fifth Assessment Report of the Intergovernmental Panel on Climate Change, edited by: Stocker, T. F., Qin, D., Plattner, G.-K., Tignor, M., Allen, S. K., Doschung, J., Nauels, A., Xia, Y., Bex, 
V., and Midgley, P. M., Cambridge University Press, 867-952, doi:10.1017/CBO9781107415324.022, 2013.

Blanchard-Wrigglesworth, E., Armour, K., Bitz, C. M., and deWeaver, E.: Persistence and inherent predictability of Arctic sea ice in a GCM ensemble and observations, J. Climate, 24, 231-250, doi:10.1175/2010JCLI3775.1, 2011a.

Blanchard-Wrigglesworth, E., Bitz, C. M., and Holland, M. M.: Influence of initial conditions and climate forcing on predicting Arctic sea ice, Geophys. Res. Lett., 38, L18503, doi:10.1029/2011GL048807, 2011b.

Boé, J. L., Hall, A., and Qu, X.: September sea-ice cover in the Arctic Ocean projected to vanish by 2100 , Nat. Geosci., 2, 341343, 2009

Cavalieri, D. J. and Parkinson, C. L.: Arctic sea ice variability and trends, 1979-2010, The Cryosphere, 6, 881-889, doi:10.5194/tc6-881-2012, 2012.

Cavalieri, D. J., Parkinson, C. L., Gloersen, P., and Zwally, H. J.: Sea Ice Concentrations from Nimbus-7 SMMR and DMSP SSM/I-SSMIS Passive Microwave Data, updated yearly, Version 1, NASA National Snow and Ice Data Center Distributed Active Archive Center, Boulder, Colorado USA, doi:10.5067/8GQ8LZQVL0VL, available at: http://nsidc.org/ data/NSIDC-0051, last access: October 2016, 1996.

Collins, M. and Allen, M. R.: On assessing the relative roles of initial and boundary conditions in interannual to decadal climate predictability, J. Climate, 21, 3104-3109, 2002.

Comiso, J. C.: Large Decadal Decline of the Arctic Multiyear Ice Cover, J. Climate, 25, 1176-1193, 2012.

Comiso, J. C.: Bootstrap Sea Ice Concentrations from Nimbus-7 SMMR and DMSP SSM/I-SSMIS, Version 2, NASA National Snow and Ice Data Center Distributed Active Archive Center, Boulder, Colorado USA, 2000, updated 2015.

Comiso, J. C., Parkinson, C. L., Gersten, R., and Stock, L.: Accelerated decline in the Arctic sea ice cover, Geophys. Res. Lett., 35, L01703, doi:10.1029/2007GL031972, 2008.

Comiso, J. C., Kwok, R., Martin, S., and Gordon, A. L.: Variability and trends in sea ice extent and ice production in the Ross Sea, J. Geophys. Res., 116, C04021, doi:10.1029/2010JC006391, 2011.

Cunningham, S. A., Kanzow, T., Rayner, D., Baringer, M. O., Johns, W., Marotzke, E. J., Longworth, H. R., Grant, E. M., Hirschi, J. J.-M., Beal, L. M., Meinen, C. S., and Bryden, H. L.: Temporal variability of the Atlantic meridional overturning circulation at 26.5 ${ }^{\circ} \mathrm{N}$, Science, 317, 935-938, 2007.

Day, J. J., Hargreaves, J. C., Annan, J. D., and Abe-Ouchi, A.: Sources of multi-decadal variability in Arctic sea ice extent, Environ. Res. Lett., 7, 034011, doi:10.1088/1748-9326/7/3/034011, 2012.

Day, J. J., Hawkins, E., and Tietsche, S.: Will Arctic sea ice thickness initialization improve seasonal forecast skill?, Geophys. Res. Lett., 41, 7566-7575, doi:10.1002/2014GL061694, 2014a.

Day, J. J., Tietsche, S., and Hawkins, E.: Pan-arctic and regional sea ice predictability: Initialization month dependence, J. Climate, 27, 4371-4390, 2014b.

Day, J. J., Tietsche, S., Collins, M., Goessling, H. F., Guemas, V., Guillory, A., Hurlin, W. J., Ishii, M., Keeley, S. P. E., Matei, D., Msadek, R., Sigmond, M., Tatebe, H., and Hawkins, E.: The Arctic Predictability and Prediction on Seasonal-to-Interannual
TimEscales (APPOSITE) data set version 1, Geosci. Model Dev., 9, 2255-2270, doi:10.5194/gmd-9-2255-2016, 2016.

Doblas-Reyes, F. J., Andreu-Burillo, I., Chikamoto, Y., GarcíaSerrano, J., Guemas, V., Kimoto, M., Mochizuki, T., Rodrigues, L. R. L., and van Oldenborgh, G. J.: Initialized near-term regional climate change prediction, Nature Communications, 4, 1715, doi:10.1038/ncomms2704, 2013.

Döös, K., Nycander, J., and Coward, A. C.: Lagrangian decomposition of the Deacon Cell, J. Geophys. Res., 113, C07028, doi:10.1029/2007JC004351, 2008.

Enfield, D. B., Mestas-Nuñez, A. M., and Trimble, P. J.: The Atlantic Multidecadal Oscillation and its relation to rainfall and river flows in the continental US, Geophys. Res. Lett., 28, 20772080, 2001.

Fetterer, F., Knowles, K., Meier, W., and Savoie, M.: Sea ice index, digital media, National Snow and Ice Data Center, Boulder, CO, 2002.

Fetterer, F., Knowles, K., Meier, W., and Savoie, M.: Sea ice index, digital media, National Snow and Ice Data Center, Boulder, CO, 2010.

Fetterer, F., Knowles, K., Meier, W., and Savoie, M.: Sea Ice Index, updated daily, Version 2, NSIDC: National Snow and Ice Data Center, Boulder, Colorado USA, doi:10.7265/N5736NV7, http: //nsidc.org/data/G02135 (last access: October 2016), 2016.

Francis, J. A. and Vavrus, S. J.: Evidence linking Arctic amplification to extreme weather in mid-latitudes, Geophys. Res. Lett., 39, L06801, doi:10.1029/2012GL051000, 2012.

Germe, A., Chevallier, M., Salas y Mélia, D., Sanchez-Gomez, E., and Cassou, C.: Interannual predictability of Arctic sea ice in a global climate model: Regional contrasts and temporal evolution, Clim. Dynam., 43, 2519-2538, doi:10.1007/s00382-014-2071-2, 2014.

Goddard, L., Kumar, A., Solomon, A., Smith, D., Boer, G., Gonzalez, P., Kharin, V., Merryfield, W., Deser, C., Mason, S. J., Kirtman, B. P., Msadek, R., Sutton, R., Hawkins, E., Fricker, T., Hegerl, G., Ferro, C. A. T., Stephenson, D. B., Meehl, G. A., Stockdale, T., Burgman, R., Greene, A. M., Kushnir, Y., Newman, M., Carton, J., Fukumori, I., and Delworth, T.: A verification framework for interannual-to-decadal predictions experiments, Clim. Dynam., 40, 245-272, doi:10.1007/s00382-0121481-2, 2013.

Goosse, H., Close, S., Dubinkina, S., Massonnet, F., Zunz, V., Vannitsem, S., Schaeybroeck, B. V., Barth, A., and Canter, M.: Understanding and predicting Antarctic sea ice variability at the decadal timescale - "PREDANTAR", available at: http://www.elic.ucl.ac.be/users/zunz/site_PREDANTAR/ en-project_results.html, last access: October 2016, 2015.

Guemas, V., Blanchard-Wrigglesworth, E., Chevallier, M., Day, J. J., Déqué, M., Doblas-Reyes, F. J., Fuckar, N. S., Germe, A., Hawkins, E., Keeley, S., Koenigk, T., Salas y Mélia, D., and Tietsche, S.: A review on Arctic sea-ice predictability and prediction on seasonal to decadal time-scales, Q. J. Roy. Meteor. Soc., 142, 546-561, doi:10.1002/qj.2401, 2016.

Ham, Y.-G., Rienecker, M. M., Suarez, M. J., Vikhliaev, Y., Zhao, B., Marshak, J., Vernieres, G., and Schubert, S. D.: Decadal prediction skill in the GEOS-5 forecast system, Clim. Dynam., 42, 1-20, 2014.

Holland, M. M. and Raphael, M. N.: Twentieth century simulation of the Southern Hemisphere climate in coupled models. Part II: 
Sea ice conditions and variability, Clim. Dynam., 26, 229-245, 2006.

Holland, M. M., Bailey, D. A., and Vavrus, S.: Inherent sea ice predictability in the rapidly changing Arctic environment of the Community Climate System Model, version 3, Clim. Dynam., 36, 1239-1253, 2011.

Holland, M. M., Blanchard-Wrigglesworth, E., Kay, J., and Vavrus, S.: Initial-value predictability of Antarctic sea ice in the Community Climate System Model 3, Geophys. Res. Lett., 40, $2121-$ 2124, doi:10.1002/grl.50410, 2013.

Holland, P. R. and Kwok, R.: Wind-driven trends in Antarctic seaice drift, Nat. Geosci., 5, 872-875, 2012.

Ishii, M. and Kimoto, M.: Reevaluation of historical ocean heat content variations with time-varying XBT and MBT depth bias corrections, J. Oceanogr., 65, 287-299, doi:10.1007/s10872-0090027-7, 2009.

Jackson, L. C., Kahana, R., Graham, T., Ringer, M. A., Woollings, T., Mecking, J. V., and Wood, R. A.: Global and European climate impacts of a slowdown of the AMOC in a high resolution GCM, Clim. Dynam., 45, 3299-3316, doi:10.1007/s00382-0152540-2, 2015.

Jeffries, M. O., Richter-Menge, J., and Overland, J. E. (Eds.): Arctic Report Card 2015, available at: http://www.arctic.noaa.gov/ reportcard (last access: December 2015), 2015.

Jung, T., Gordon, N., Klebe, S., Bauer, P., Bromwich, D. H., Day, J., Doblas-Reyes, F., Fairall, C., Hines, K., Holland, M., Iversen, T., Lemke, P., Mills, B., Nurmi, P., Renfrew, I., Smith, G., Svensson, G., and Tolstykh, M.: WWRP Polar Prediction Project implementation plan, WWRP/PPP No. 2, http://polarprediction.net/ en/documents/, last access: 29 August 2014, 2013.

Kattsov, V., Ryabinin, V., Overland, J., Serreze, M., Visbeck, M., Walsh, J., Meier, W., and Zhang, X.: Arctic sea ice change: A grand challenge of climate science, J. Glaciol., 56, 1115-1121, 2010

Keenlyside, N. S., Latif, M., Jungclaus, J., Kornblueh, L., and Roeckner, E.: Advancing decadal-scale climate prediction in the North Atlantic sector, Nature, 453, 84-88, doi:10.1038/nature06921, 2008.

Kharin, V. V., Boer, G. J., Merryfield, W. J., Scinocca, J. F., and Lee, W.-S.: Statistical adjustment of decadal predictions in a changing climate, Geophys. Res. Lett., 39, L19705, doi:10.1029/2012GL052647, 2012.

Kim, H.-M., Webster, P. J., and Curry, J. A.: Evaluation of short-term climate change prediction in multi-model CMIP5 decadal hindcasts, Geophys. Res. Lett., 39, L10701, doi:10.1029/2012GL051644, 2012.

Koenigk, T. and Mikolajewicz, U.: Seasonal to interannual climate predictability in mid and high northern latitudes in a global coupled model, Clim. Dynam., 32, 783-798, 2009.

Koenigk, T., Mikolajewicz, U., Haak, H., and Jungclaus J.: Arctic Freshwater Export in the 20th and 21st Century, J. Geophys. Res., 112, GS04S41, doi:10.1029/2006JG000274, 2007.

Koenigk, T., Beatty, C. K., Caian, M., Döscher, R., and Wyser, K.: Potential decadal predictability and its sensitivity to sea ice albedo parameterization in a global coupled model, Clim. Dynam., 38, 2389-2408, 2012.

Kurtz, N. T. and Markus, T.: Satellite observations of Antarctic sea ice thickness and volume, J. Geophys. Res., 117, C08025, doi:10.1029/2012JC008141, 2012.
Kwok, R.: Recent changes of the Arctic Ocean sea ice motion associated with the North Atlantic Oscillation, Geophys. Res. Lett. 27, 775-778, 2000.

Kwok, R., Cunningham, G. F., Wensnahan, M., Rigor, I., Zwally, H. J., and Yi, D.: Thinning and volume loss of the Arctic Ocean sea ice cover: 2003-2008, J. Geophys. Res., 114, C07005, doi:10.1029/2009JC005312, 2009.

Lindsay, R. W. and Zhang, J.: The Thinning of Arctic Sea Ice, 19882003: Have We Passed a Tipping Point?, J. Climate, 18, 48794894, 2005.

Liu, J. and Curry, J. A.: Accelerated warming of the Southern Ocean and its impacts on the hydrological cycle and sea ice, P. Natl. Acad. Sci. USA, 107, 14987-14992, 2010.

Liu, J., Curry, J. A., and Martinson, D. G.: Interpretation of recent Antarctic sea ice variability, Geophys. Res. Lett., 31, L02205, doi:10.1029/2003GL018732, 2004.

Liu, J., Curry, J. A., Wang, H., Song, M., and Horton, R.: Impact of declining Arctic sea ice on winter snowfall, P. Natl. Acad. Sci. USA, 109, 4074-4079; Corrigendum, 109, 6781-6783, 2012.

Liu, J., Song, M., Horton, R. M., and Hu, Y.: Reducing spread in climate model projections of a September icefree Arctic, P. Natl. Acad. Sci. USA, 110, 12571-12576, doi:10.1073/pnas.1219716110, 2013.

Liu, J. F., Yuan, X., Rind, D., and Martinson, D.: Mechanism study of the ENSO and southern high latitude climate teleconnections, Geophys. Res. Lett., 29, 1679, doi:10.1029/2002GL015143, 2002.

Lumpkin, R. and Speer, K.: Global ocean meridional overturning, J. Phys. Oceanogr., 37, 2550-2562, 2007.

Mahajan, S., Zhang, R., and Delworth, T. L.: Impact of the Atlantic Meridional Overturning Circulation (AMOC) on Arctic surface air temperature and sea-ice variability, J. Climate, 24, 6573-6581, doi:10.1175/2011JCLI4002.1, 2011.

Massonnet, F., Fichefet, T., Goosse, H., Bitz, C. M., PhilipponBerthier, G., Holland, M. M., and Barriat, P.-Y.: Constraining projections of summer Arctic sea ice, The Cryosphere, 6, 13831394, doi:10.5194/tc-6-1383-2012, 2012.

McCarthy, G. D., Smeed, D. A., Johns, W. E., Frajka-Williams, E., Moat, B. I., Rayner, D., Baringer, M. O., Meinen, C. S., and Bryden, H. L.: Measuring the Atlantic meridional overturning circulation at $26^{\circ} \mathrm{N}$, Prog. Oceanogr., 130, 91-111, 2015.

Meehl, G. A., Goddard, L., Murphy, J., Stouffer, R. J., Boer, G., Danabasoglu, G., Dixon, K., Giorgetta, M. A., Greene, A. M., Hawkins, E., Hegerl, G., Karoly, D., Keenlyside, N., Kimoto, M., Kirtman, B., Navarra, A., Pulwarty, R., Smith, D., Stammer, D., and Stockdale, T.: Decadal Prediction, B. Am. Meteorol. Soc., 90, 1467-1485, doi:10.1175/2009BAMS2778.1, 2009.

Meehl, G. A., Hu, A., Arblaster, J. M., Fasullo, J., and Trenberth, K. E.: Externally Forced and Internally Generated Decadal Climate Variability Associated with the Interdecadal Pacific Oscillation, J. Climate, 26, 7298-7310, doi:10.1175/JCLI-D-1200548.1, 2013

Merryfield, W. J., Lee, W.-S., Boer, G. J., Kharin, V. V., Scinocca, J. F., Flato, G. M., Ajayamohan, R. S., Fyfe, J. C., Tang, Y., and Polavarapu, S.: The Canadian Seasonal to Interannual Prediction System. Part I: Models and Initialization, Mon. Weather Rev., 141, 2910-2945, doi:10.1175/MWR-D-12-00216.1, 2013.

Mochizuki, T., Chikamoto, T., Kimoto, M., Ishii, M., Tatebe, H., Komuro, Y., Sakamoto, T., Watanabe, M., and Mori, M.: Decadal 
prediction using a recent series of MIROC global climate models, J. Meteorol. Soc. Jpn., 90, 373-383, 2012.

Msadek, R., Vecchi, G. A., Winton, M., and Gudgel, R. G.: Importance of initial conditions in seasonal predictions of Arctic sea ice extent, Geophys. Res. Lett., 41, 5208-5215, doi:10.1002/2014GL060799, 2014.

Müller, W. A., Baehr, J., Haak, H., Jungclaus, J. H., Kröger, J., Matei, D., Notz, D., Pohlmann, H., von Storch, J.-S., and Marotzke, J.: Forecast skill of multi-year seasonal means in the decadal prediction system of the Max Planck Institute for Meteorology, Geophys. Res. Lett., 39, L22707, doi:10.1029/2012GL053326, 2012.

National Research Council: Seasonal to Decadal Predictions of Arctic Sea Ice: Challenges and Strategies, The National Academies Press, Washington, DC, 2012.

Parkinson, C. L. and Cavalieri, D. J.: Antarctic sea ice variability and trends, 1979-2010, The Cryosphere, 6, 871-880, doi:10.5194/tc-6-871-2012, 2012.

Pohlmann, H., Jungclaus, J. H., Köhl, A., Stammer, D., and Marotzke, J.: Initialized decadal climate predictions with the GECCO oceanic synthesis: Effects on the North Atlantic, J. Climate, 22, 3926-3938, 2009.

Polvani, L. M. and Smith, K. L.: Can natural variability explain observed Antarctic sea ice trends? New modeling evidence from CMIP5, Geophys. Res. Lett., 40, 3195-3199, doi:10.1002/grl.50578, 2013.

National Research Council: Seasonal to Decadal Predictions of Arctic Sea Ice: Challenges and Strategies, The National Academies Press, Washington, DC, doi:10.17226/13515, 2012.

Rigor, I. G. and Wallace, J. M.: Variations in age of Arctic sea ice and summer sea-ice extent, Geophys. Res. Lett., 31, L09401, doi:10.1029/2004GL019492, 2004.

Serreze, M. C., Holland, M. M., and Stroeve, J.: Perspectives on the Arctic's shrinking sea-ice cover, Science, 315, 1533-1536, 2007.

Sigmond, M. and Fyfe, J. C.: Has the ozone hole contributed to increased Antarctic sea ice extent?, Geophys. Res. Lett., 37, L18502, doi:10.1029/2010GL044301, 2010.

Shu, Q., Song, Z., and Qiao, F.: Assessment of sea ice simulations in the CMIP5 models, The Cryosphere, 9, 399-409, doi:10.5194/tc9-399-2015, 2015.

Smeed, D. A., McCarthy, G. D., Cunningham, S. A., FrajkaWilliams, E., Rayner, D., Johns, W. E., Meinen, C. S., Baringer, M. O., Moat, B. I., Duchez, A., and Bryden, H. L.: Observed decline of the Atlantic meridional overturning circulation 20042012, Ocean Sci., 10, 29-38, doi:10.5194/os-10-29-2014, 2014.

Smith, D. M., Cusack, S. A., Colman, W., Folland, C. K., Harris, G. R., and Murphy, J. M.: Improved surface temperature prediction for the coming decade from a global climate model, Science, 317, 796-799, 2007.

Smith, L. C. and Stephenson, S. R.: New Trans-Arctic shipping routes navigable by mid-century, P. Natl. Acad. Sci. USA, 110, E1191-E1195, doi:10.1073/pnas.1214212110, 2013.

Stroeve, J., Holland, M. M., Meier, W., Scambos, T., and Serreze, M.: Arctic sea ice decline: Faster than forecast, Geophys. Res. Lett., 34, L09501, doi:10.1029/2007GL029703, 2007.

Stroeve, J. C., Kattsov, V., Barrett, A., Serreze, M., Pavlova, T., Holland, M. M., and Meier, W. N.: Trends in Arctic sea ice extent from CMIP5, CMIP3 and observations, Geophys. Res. Lett., 39, L16502, doi:10.1029/2012GL052676, 2012.
Stroeve, J. C., Hamilton, L. C., Bitz, C. M., and BlanchardWrigglesworth, E.: Predicting September sea ice: Ensemble skill of the SEARCH Sea Ice Outlook 2008-2013, Geophys. Res. Lett., 41, 2411-2418, doi:10.1002/2014GL059388, 2014a.

Stroeve, J. C., Markus, T., Boisvert, L., Miller, J., and Barrett, A.: Changes in Arctic melt season and implications for sea ice loss, Geophys. Res. Lett., 41, 1216-1225, doi:10.1002/2013g1058951, 2014b.

Taylor, K. E., Stouffer, R. J., and Meehl, G. A.: An overview of CMIP5 and the experiment design, B. Am. Meteorol. Soc., 93, 485-498, 2012.

Tietsche, S., Notz, D., Jungclaus, J. H., and Marotzke, J.: Predictability of large interannual Arctic sea-ice anomalies, Clim. Dynam., 41, 2511-2526, doi:10.1007/s00382-013-1698-8, 2013.

Tietsche, S., Day, J. J., Guemas, V., Hurlin, W. J., Keeley, S. P. E., Matei, D., Msadek, R., Collins, M., and Hawkins, E.: Seasonal to interannual Arctic sea ice predictability in current global climate models, Geophys. Res. Lett., 41, 1035-1043, doi:10.1002/2013GL058755, 2014.

Turner, J., Comiso, J. C., Marshall, G. J., Lachlan-Cope, T. A., Bracegirdle, T., Maksym, T., Meredith, M. P., Wang, Z., and Orr, A.: Non-annular atmospheric circulation change induced by stratospheric ozone depletion and its role in the recent increase of Antarctic sea ice extent, Geophys. Res. Lett., 36, L08502, doi:10.1029/2009GL037524, 2009.

Turner, J., Bracegirdle, T. J., Phillips, T., Marshall, G. J., and Scott Hosking, J.: An initial assessment of Antarctic sea ice extent in the CMIP5 models, J. Climate, 26, 1473-1484, 2013.

Vera, C., Barange, M., Dube, O. P., Goddard, L., Griggs, D., Kobysheva, N., Odada, E., Parey, S., Polovina, J., Poveda, G., Seguin, B., and Trenberth, K.: Needs assessment for climate information on decadal time scales and longer, in: World Climate Conference - 3, Geneva, Switzerland, 31 August-4 September 2009, edited by: Sivakumar, M. V. K., Nyenzi, B. S., and Tyagi, A., Procedia Environmental Sciences, 1, 275-286, doi:10.1016/j.proenv.2010.09.017, 2010.

Wang, M. and Overland, J. E.: A sea ice free summer Arctic within 30 years?, Geophys. Res. Lett., 36, L07502, doi:10.1029/2009GL037820, 2009.

Wang, M. and Overland, J. E.: A sea ice free summer Arctic within 30 years: An update from CMIP5 models, Geophys. Res. Lett., 39, L18501, doi:10.1029/2012GL052868, 2012.

WCRP: Coupled Model Intercomparison Project phase 5 (CMIP5) model output, World Climate Research Programme's (WCRP) Working Group on Coupled Modeling, available at: http:// cmip-pcmdi.llnl.gov/cmip5/, last access: October 2016.

Wendler, G., Chen, L., and Moore, B.: Recent sea ice increase and temperature decrease in the Bering Sea area, Alaska, Theor. Appl. Climatol., 117, 393-398, 2014.

Zhang, J.: Increasing Antarctic sea ice under warming atmospheric and oceanic conditions, J. Climate, 20, 2515-2529, 2007.

Zhang, R.: Mechanisms for low-frequency variability of summer Arctic sea ice extent, P. Natl. Acad. Sci. USA, 112, 4570-4575, doi:10.1073/pnas.1422296112, 2015.

Zhang, X.: Sensitivity of Arctic summer sea ice coverage to global warming forcing: Towards reducing uncertainty in arctic climate change projections, Tellus A, 62, 220-227, 2010.

Zhang, J. and Zhang, R.: On the Evolution of Atlantic Meridional Overturning Circulation (AMOC) Fingerprint and Implications 
for Decadal Predictability in the North Atlantic, Geophys. Res. Lett., 42, 5419-5426, doi:10.1002/2015GL064596, 2015.

Zhang, J., Woodgate, R., and Moritz, R.: Sea ice response to atmospheric and oceanic forcing in the Bering Sea, J. Phys. Oceanogr., 40, 1729-1747, doi:10.1175/2010JPO4323.1, 2010.
Zunz, V., Goosse, H., and Massonnet, F.: How does internal variability influence the ability of CMIP5 models to reproduce the recent trend in Southern Ocean sea ice extent?, The Cryosphere, 7, 451-468, doi:10.5194/tc-7-451-2013, 2013.

Zunz, V., Goosse, H., and Dubinkina, S.: Impact of the initialisation on the predictability of the Southern Ocean sea ice at interannual to multi-decadal timescales, Clim. Dynam., 44, 2267-2286, 2015 . 